\title{
Phosphorylation of SMC1 is a critical downstream event in the ATM-NBS1-BRCA1 pathway
}

\author{
Risa Kitagawa, ${ }^{1}$ Christopher J. Bakkenist, ${ }^{1}$ Peter J. McKinnon, ${ }^{2}$ and Michael B. Kastan ${ }^{1,3}$ \\ ${ }^{1}$ Department of Hematology-Oncology and ${ }^{2}$ Department of Genetics and Tumor Cell Biology, St. Jude Children's Research \\ Hospital, Memphis, Tennessee 38018, USA
}

The ATM protein kinase is activated by intermolecular autophosphorylation in response to DNA damage and initiates cellular signaling pathways that facilitate cell survival and reduce chromosomal breakage. Here, we show that NBS1 and BRCA1 are required for the recruitment of previously activated ATM to the sites of DNA breaks after ionizing irradiation, and that this recruitment is required for the phosphorylation of SMC1 by ATM. To explore the functional importance of SMC1 phosphorylation, murine cells were generated, in which the two damage-induced phosphorylation sites in SMC1 are mutated. Although these cells demonstrate normal phosphorylation and focus formation of ATM, NBS1, and BRCA1 proteins after IR, they exhibit a defective S-phase checkpoint, decreased survival, and increased chromosomal aberrations after DNA damage. These observations suggest that many of the abnormal stress responses seen in cells lacking ATM, NBS1, or BRCA1 result from a failure of ATM migration to sites of DNA breaks and a resultant lack of SMC1 phosphorylation.

[Keywords: ATM; NBS1; SMC1; BRCA1; DNA damage]

Supplemental material is available at http://www.genesdev.org.

Received March 3, 2004; revised version accepted April 23, 2004.

DNA damage causes cancer, is used to treat cancer, and is responsible for many of the side effects of cancer therapies. Significant progress has been made in recent years elucidating the molecular controls of cellular responses to DNA damage in mammalian cells (Kastan and Lim 2000; Zhou and Elledge 2000). Many of the insights that we have gained into mechanisms involved in cellular DNA-damage-response pathways have come from studies of human cancer susceptibility syndromes that are altered in DNA-damage responses. Gene products such as p53, ATM, NBS1, and BRCA1 are mutated in various human cancer susceptibility syndromes and play critical roles in cellular responses to DNA damage. ATM (Ataxiatelangiectasia, mutated) is a protein kinase that is activated as an initiating event in cells following DNA breakage, and subsequently, phosphorylates numerous proteins to induce cell cycle arrests, to reduce chromosomal breakage, and to enhance cell survival (Shiloh and Kastan 2001). Although effects on DNA repair processes seem likely, the mechanisms by which this signaling pathway affects cell survival and chromosomal stability after irradiation remain to be elucidated.

${ }^{3}$ Corresponding author.

E-MAIL michael.kastan@stjude.org; FAX (901) 495-3966.

Article published online ahead of print. Article and publication date are at http://www.genesdev.org/cgi/doi/10.1101/gad.1200304.
SMC1 is a member of the structural maintenance of chromosomes family. It was originally identified in Saccharomyces sereviciae as a component of cohesin, a protein complex that is required for maintenance of sister chromatid cohesion (Michaelis et al. 1997). SMC1 was also reported to be present in a biochemically defined mammalian protein complex, called RC-1, which promotes DNA recombination (Jessberger et al. 1996; Stursberg et al. 1999). Studies of cohesin mutants in yeast and some vertebrate cells suggested a role for the cohesin complex in genome integrity and DNA repair (Sjogren and Nasmyth 2001). SMC1 was recently shown to be a target of the ATM kinase with phosphorylation of Ser 957 and Ser 966 of SMC1 occurring in an ATM-dependent manner after ionizing irradiation (Kim et al. 2002; Yazdi et al. 2002). Because SMC1-null mammalian cells did not exist, studies exploring the functional ramifications of these phosphorylations were limited to dominant-inhibitory effects caused by overexpression of a phosphorylation-mutant SMC1 construct. Interestingly, overexpression of such an SMC1 mutant abrogated the IR-induced S-phase checkpoint and caused radiosensitivity (Kim et al. 2002). Because lack of phosphorylation of p53, NBS1, and BRCA1 by ATM have no significant effects on radiosensitivity (Slichenmyer et al. 1993; Lim et al. 2000; Xu et al. 2001, 2002), these results suggested 
that the only target of ATM whose phosphorylation directly affects cell survival was SMC1.

To more definitively demonstrate the functional role(s) of SMC1 phosphorylation in DNA-damage responses, additional studies were performed characterizing the relationships between ATM activation, the NBS1 and BRCA1 proteins, and SMCl phosphorylation. In addition, mice with targeted modifications of the SMC1 phosphorylation sites were generated. These two approaches led to a clarification of the order of dependencies of the molecular events that occur in this IR-induced signaling pathway. ATM activation appears to be the initiating event in cells following DNA-strand breakage, although the magnitude of this activation is influenced by the presence of NBS1 at low doses of irradiation. NBS1 and BRCA1 migrate to the sites of DNA breaks independently of ATM activation, but once these proteins are at the breaks, their presence is required to recruit the activated ATM kinase to the site of the break. Once activated ATM is recruited to the break by NBS1 and BRCA1, ATM can phosphorylate SMC1 on Ser 957 and Ser 966. In cells from the Smc1 mutant knock-in mouse, ATM activation and phosphorylation of NBS1 and BRCA1 occur normally, but abnormalities in DNAdamage responses remain. Thus, SMC1 phosphorylation appears to be the critical downstream target in this pathway that mediates cell survival and chromosomal stability after DNA damage.

\section{Results}

Distinct dose-dependencies for phosphorylation of ATM versus its targets after IR

We previously noted that activation of ATM in cells after DNA damage as measured by autophosphorylation of Ser 1981 was quite extensive and was already maximal at doses of IR as low as 0.5 Gy (Bakkenist and Kastan 2003). Here, we extended these observations by comparing the dose responsiveness of ATM phosphorylation with that of ATM substrates in normal human diploid fibroblasts $15 \mathrm{~min}$ after exposure to ionizing radiation. As previously noted, ATM was already maximally phosphorylated at the low dose of $1 \mathrm{~Gy}$, with no further increase seen up to doses as high as $30 \mathrm{~Gy}$ (Fig. 1A). At this early time point after irradiation, increases in $\mathrm{p} 53$ protein levels and phosphorylation of p53 at this time are virtually totally dependent on ATM kinase activity (Canman et al. 1994, 1998; Siliciano et al. 1997). Similar to the dose responsiveness of ATM autophosphorylation, phosphorylation of p53 on Ser 15 at this early time point was maximal at doses of 1-3 Gy with little or no further increase up to doses of $30 \mathrm{~Gy}$. In contrast to phosphorylation of ATM and p53, phosphorylation of SMC1 (Ser 957), NBS1 (Ser 343), and H2AX (Ser 139) all increased in a dose-dependent manner, with continued increases in phosphorylation up through 30 Gy IR (Fig. 1A). Because the number of DNA-strand breaks continuously increases with increasing dose of IR, and because phosphorylated $\mathrm{H} 2 \mathrm{AX}$ protein and NBS1 protein form foci at the sites of DNA double-strand breaks, there is a strong correlation between the number of DNA breaks and the amount of phosphorylation of H2AX, NBS1, and SMC1 proteins. In contrast, there is not a correlation between initial phosphorylation of ATM and p53 and the number of DNA strand breaks, at least not beyond doses in the range of 1-3 Gy IR.

Our previous work also suggested that ATM is not activated directly by binding to the sites of DNA breaks. The lack of correlation between dose and the number of DNA breaks seen here is consistent with that model. Rather, we suggested that changes in higher-order chromatin structure provide the direct signal for ATM activation, and we reported cellular treatments that could activate ATM in the absence of detectable DNA strand breaks (Bakkenist and Kastan 2003). Exposure of cells to mild hypotonic conditions or to the topoisomerase II inhibitor, chloroquine, modifies chromatin structure without inducing detectable DNA breaks. Using such chromatin-modifying treatments, we again observed levels of activation of ATM and p53 similar to that seen in cells exposed to submaximal, low-dose irradiation (Fig. 1B). In contrast, these chromatin-modifying treatments do not result in detectable phosphorylation of NBS1, SMC1 (Fig. 1B), or H2AX (Bakkenist and Kastan 2003; Supplementary Fig. S2). These observations suggest a linkage, and perhaps dependency, between DNA-strand breaks and the ATM-mediated phosphorylation of NBS1, H2AX, and SMC1, but no such relationship for the initial phosphorylation of ATM and p53. Also consistent with these concepts is the observation that phosphorylated p53 exhibits a diffuse cellular distribution following both IR and chloroquine treatment (Supplementary Fig. S2).

\section{The influence of NBS1 protein on ATM activation, localization, and activity}

To further define the determinants of signaling in this damage-response pathway, we explored the interdependencies of ATM, NBS1, and SMC1 phosphorylation. Consistent with previous observations (Kim et al. 2002; Yazdi et al. 2002), phosphorylation of SMC1 by ATM was absent in cells lacking full-length NBS1 protein and was restored by introduction of NBS1 into these cells (Fig. 2A). The dose dependency of SMC1 phosphorylation was also restored by this introduction of wild-type NBS1 protein. It has previously been reported that cells lacking NBS1 are able to measurably increase ATM kinase activity following irradiation (Lim et al. 2000), but recent publications have suggested an important role for NBS1 in the activation and autophosphorylation of ATM in certain settings (Carson et al. 2003; Mochan et al. 2003; Uziel et al. 2003; Horejsi et al. 2004). To test whether the NBS1-dependent phosphorylation of SMC1 reflected a role for NBS1 protein in the activation of ATM, phosphorylation of ATM was also assessed in these cells. The amount of phosphorylated ATM was not significantly affected by the presence or absence of fulllength NBS1 after IR doses of 1 Gy or above. In contrast, 


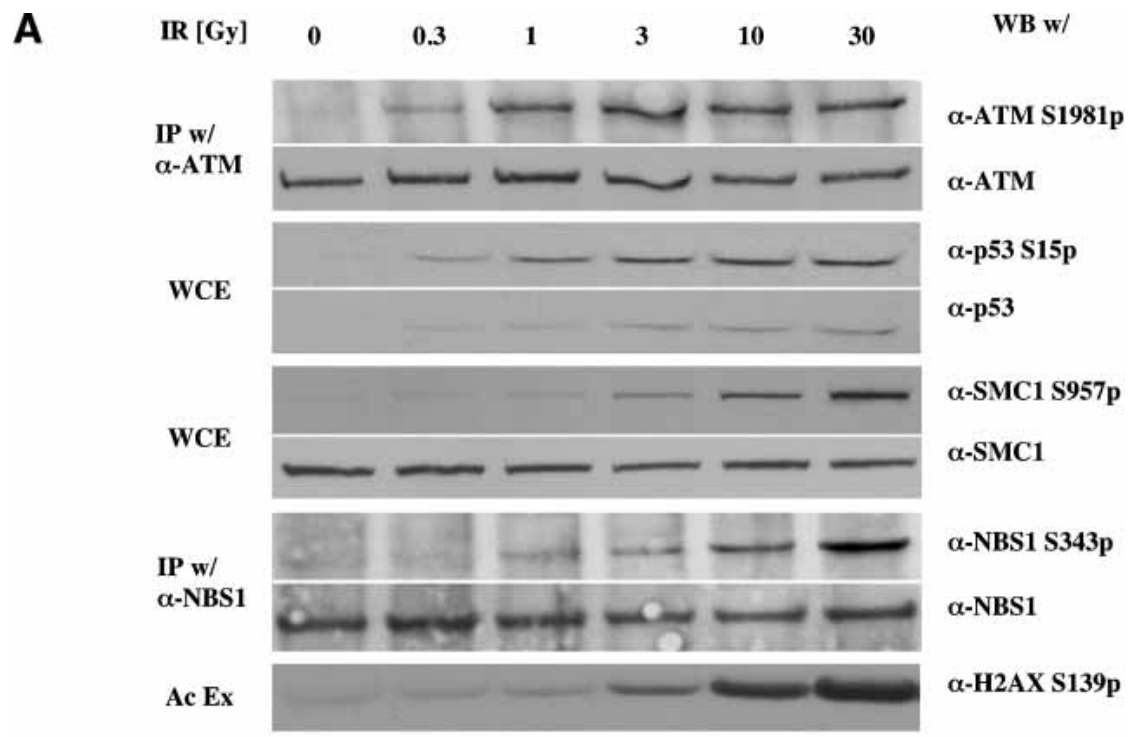

B
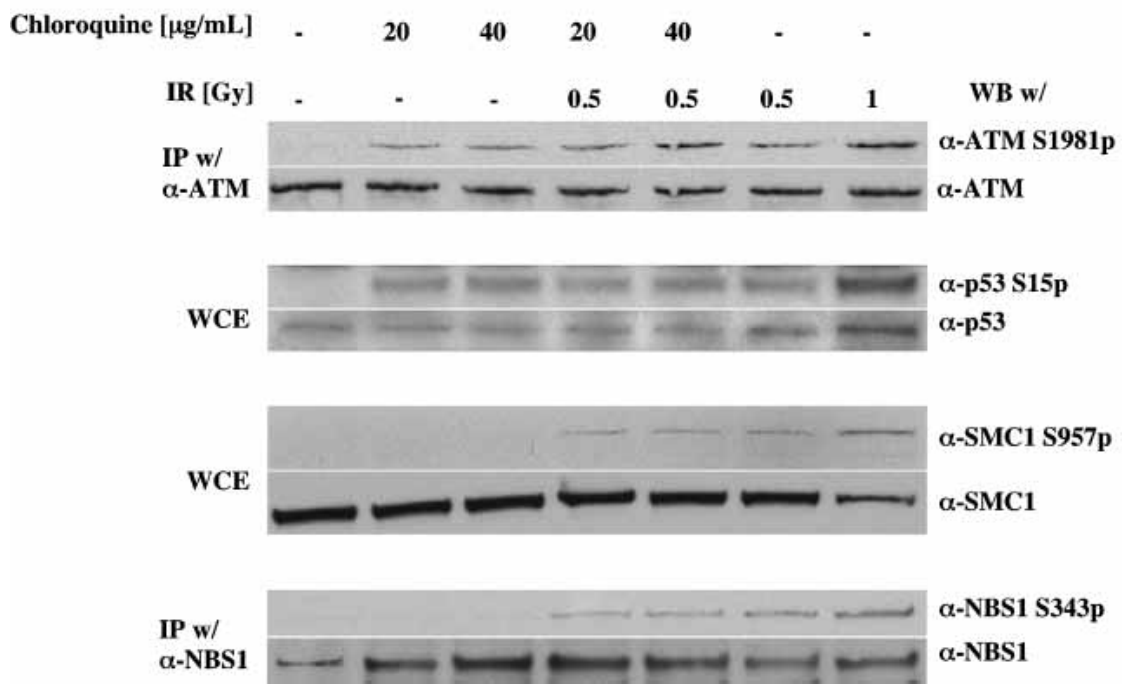

$\alpha$-NBS1 S343p $\alpha-\mathrm{NBS1}$
Figure 1. Dose dependencies of ATM activation and phoshorylation of ATM substrates. (A) Human primary fibroblast cells at early passage $(<10)$ were exposed to indicated doses of ionizing irradiation and harvested $15 \mathrm{~min}$ later. Total and phosphorylated ATM and NBS1 were assessed by immunoblots after immunoprecipitation. Total and phosphorylated p53 and SMC1 were assessed by immunoblots of whole-cell lystates (WCE). Phophorylated histone H2AX was immunoblotted after acid cellular extraction (see Materials and Methods). (B) Human primary fibroblast cells at early passage $(<10)$ were exposed to indicated doses of chloroquine for $4 \mathrm{~h}$, then exposed as indicated to ionizing irradiation. Fifteen minutes after irradiation, cells were collected, and immunoblot analysis was performed as indicated. however, at IR doses that submaximally activate ATM (e.g., 0.3 Gy), cells lacking full-length NBS1 protein exhibited decreased amounts of phosphorylated ATM (Fig. 2A). A time-course evaluation demonstrated that this quantitative difference is not simply attributable to a delay in ATM phosphorylation in the absence of fulllength NBS1 protein (Fig. 2B).

Although activated ATM was readily detectable in NBS1-deficient cells at doses at or above $1 \mathrm{~Gy}$, SMC1 phosphorylation remained minimal in these cells, even following higher doses of IR (Fig. 2A). This result suggested the possibility that although ATM can be activated in cells lacking normal NBS1 protein, the accessibility of activated ATM kinase to SMC1 protein after IR might be altered in these cells. To explore this possibility, we examined the subcellular localization of activated ATM and H2AXy in cells lacking or containing full-length NBS1 protein. Immunofluorescence revealed the expected foci of both $\mathrm{H} 2 \mathrm{AX} \gamma$ and activated ATM following irradiation of NBS1-deficient cells complemented with full-length NBS1 protein (Fig. 2C). Further, the foci containing phosphorylated ATM colocalize with H2AX $\gamma$ foci, consistent with the concept that the phosphorylated ATM has migrated to the sites of DNA breaks in these cells. As reported previously (Girard et al. 2002), IR-induced foci containing H2AX $\gamma$ were not affected by loss of functional NBS1, presumably because H2AX can also be phosphorylated by other PIKK family members, such as ATR and DNA-PK. The presence of H2AX $\gamma$ foci in irradiated AT cells (Supplementary Fig. $\mathrm{S} 1$ ) is consistent with this concept. In contrast, foci containing phosphorylated ATM were not detected in cells lacking full-length NBS1 protein. Consistent with our immunoblotting analysis, however, phosphorylated ATM was easily detectable by immunostaining in these cells. Instead of foci, the anti-ATMS1981P antibody exhibited a diffuse immunostaining pattern in NBS1-deficient cells, corresponding to the DAPI staining in the 
Kitagawa et al.

A

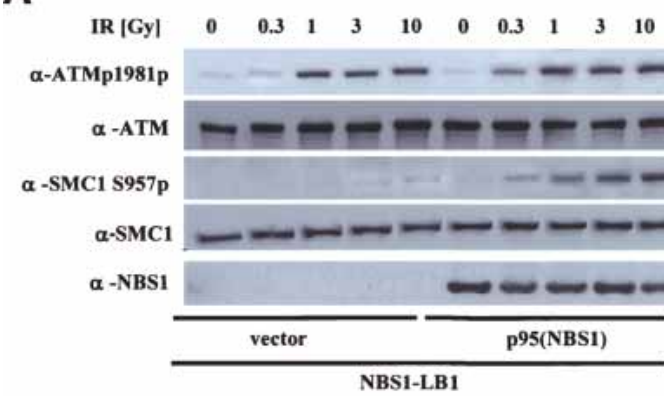

C

IR

B

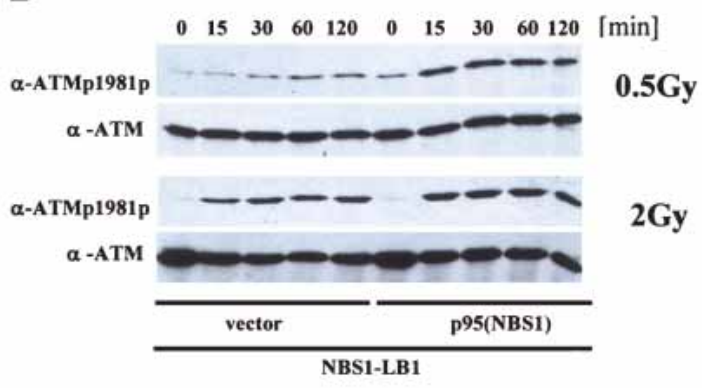

$\gamma$-H2AX ATMS1981p

DAPI

NBS1-LB1[vec]

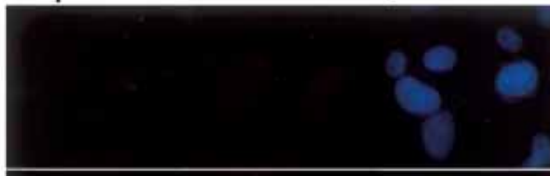

NBS1-LB1[p95]

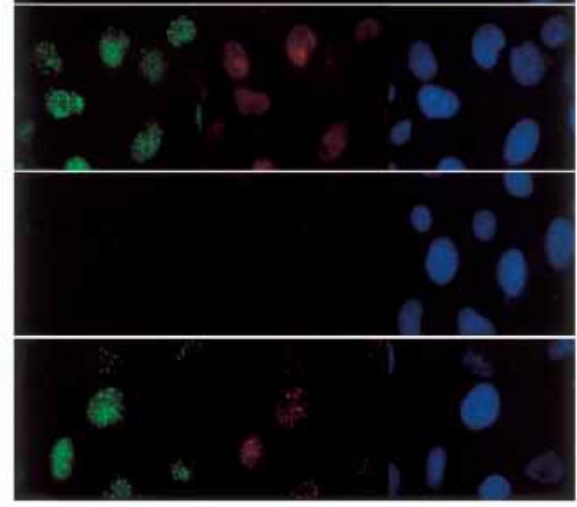

D
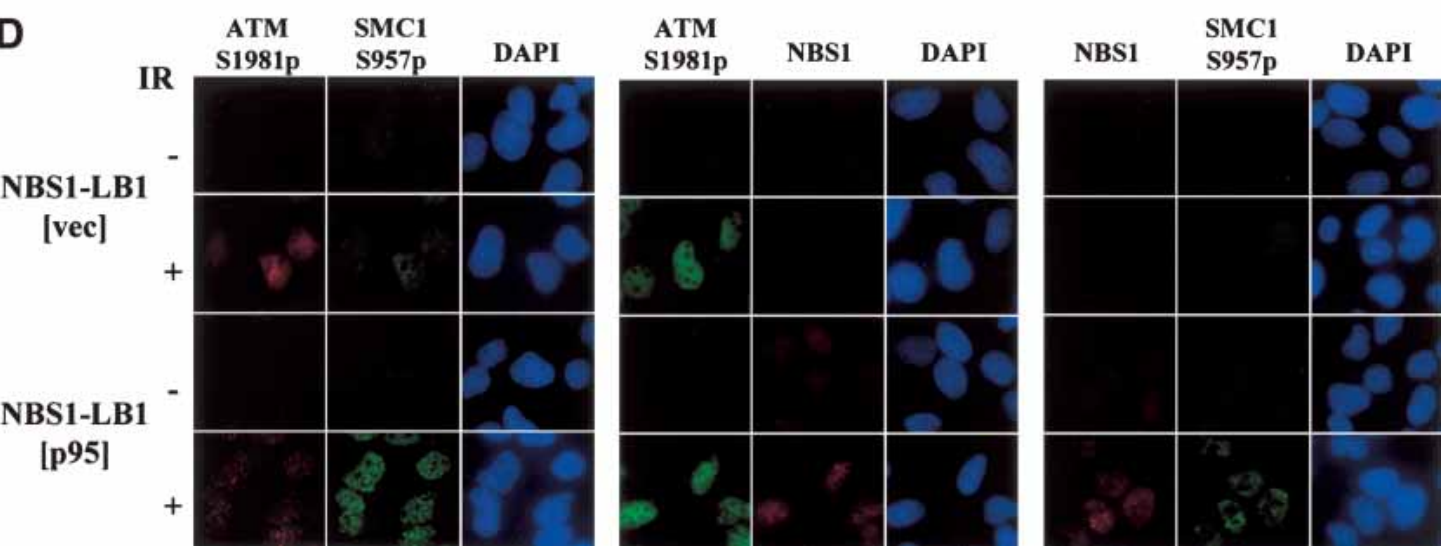

Figure 2. Influence of NBS1 on IR-induced phosphorylation and localization of ATM and ATM substrates. (A) NBS1-LB1 cells with [p95(NBS1)] or without (vector) stable retroviral complementation with the $p 95 / N B S 1$ gene were exposed to indicated doses of ionizing irradiation and cellular extracts analyzed by immunoblotting. Total and phosphorylated ATM and SMC1 were assessed by immunoblotting after immunoprecipitation, and total cellular NBS1 was assessed by immunoblot. (B) Autophosphorylation of ATM in NBS1-deficient cells exposed to a low dose of ionizing radiation. Total and phosphorylated ATM was assessed by immunoblot after immunoprecipitation in cells collected at the indicated times after exposure to 0.5 or 2 Gy of IR. (C) Subcellular localization of H2AX and phophorylated ATM in NBS1-deficient or -proficient cells. Cells were fixed 15 min after 0 Gy (IR-) or 5 Gy (IR+) of $\gamma$ irradiation, and then analyzed by immunofluorescence with the indicated antibodies. DNA was visualized by staining with DAPI. (D) Subcellular localization of phosphorylated ATM, phosphorylated SMC1, and NBS1 as a function of NBS1 status. Cells were fixed 15 min after 0 Gy (IR-) or $5 \mathrm{~Gy}(\mathrm{IR}+)$, then costained with pairs of antibodies as indicated. DNA was visualized by staining with DAPI. For costaining with NBS1 antibodies, mouse monoclonal antibodies to ATMS1981p were used instead of the rabbit polyclonal antibodies that were used for other experiments in this study. 
nuclei, and the intensity of staining was significantly greater than that seen in unirradiated cells (Fig. 2C).

The immunoblotting data combined with the immunofluorescence results demonstrate that ATM is activated following IR in cells lacking functional NBS1, but that the phosphorylated ATM does not appropriately localize to the sites of DNA double-strand breaks in the absence of functional NBS1 protein. A failure of activated ATM to localize to DNA strand breaks following IR in cells lacking NBS1 protein would be expected to lead to problems in the ability of ATM to phosphorylate substrates at the strand breaks. Because ATM is activated relatively normally in NBS1-deficient cells at doses $>1$ Gy, but phosphorylation of SMC1 protein is still defective in these cells, it is reasonable to predict that ATM phosphorylates SMC1 at the sites of DNA breaks, and that this process is dependent on NBS1 protein. In support of this concept, a monoclonal antibody that specifically recognizes phosphorylated Ser 957 in SMC1 localized to foci after IR in cells containing wildtype NBS1, but not in cells lacking full-length NBS1 protein (Fig. 2D). The SMC1 foci colocalized both with foci of phospho-ATM and with foci of NBS1. Because p53 is phosphorylated by ATM in the nucleoplasm and not at the sites of DNA breaks, the observation that $\mathrm{p} 53$ phosphorylation remains largely normal in these NBS1-deficient cells (Lim et al. 2000) is also consistent with the model and demonstrates that ATM is activated in NBS cells.

\section{$B R C A 1$ is also required for localization of activated ATM to DNA breaks and for SMC1 phosphorylation}

In our initial studies, we found that SMC1 phosphorylation after IR was also decreased in cells lacking BRCA1 function (Kim et al. 2002). We inquired whether the role of BRCA1 in SMC1 phosphorylation was similar to the role of NBS1 and resulted from effects on the localization of activated ATM after IR. Exposure of HCC1937 cells, which lack full-length BRCA1, to ionizing radiation, resulted in readily detectable phosphorylation and activation of ATM protein (Fig. 3A). Introduction of full-length BRCA1 protein into these cells did not significantly alter the amount of ATM activation. In contrast, SMC1 phosphorylation was markedly reduced in the irradiated parental HCC1937 cells, and transfection of full-length BRCA1 increased IR-induced SMC1 phosphorylation (Fig. 3A). As was observed in Figure 1, the amount of SMC1 phosphorylation continued to increase with increasing dose of IR, whereas ATM activation was already maximal at doses of 1-3 Gy. Immunofluorescence analysis revealed a significant increase in staining with the ATMS1981p antibody after IR in both parental and complemented HCC1937 cells, but there was a marked difference in staining pattern. Parental cells exhibited primarily diffuse staining after IR, whereas phosphorylated ATM formed obvious foci in the BRCA1-complemented cells (Fig. 3B). These results demonstrate that ATM is activated prior to formation of foci containing NBS1 or BRCA1, and that both NBS1 and BRCA1 are required for the recruitment of activated ATM to the sites of DNA double-strand breaks. Thus, conditions that lead to the recruitment of activated ATM to foci are the same conditions associated with efficient phosphorylation of SMC1 after IR.

It has been reported that BRCA 1 is primarily expressed in S phase and G2 (Ruffner and Verma 1997), thus raising the question of the importance of BRCA1 protein for recruitment of activated ATM to DNA breaks during G1. We found that BRCA1 protein levels are low, but not absent, in human primary fibroblast cells in G1 (Supplementary Fig. S3B), but that foci of phosphorylated ATM are still evident in these G1 cells (Supplementary Fig. S3A). HCC1937 cells lack ATM phospho-foci in both G1 and $\mathrm{S}$ phase after IR and complementation of BRCA1 restores the ATM foci in both cell cycle phases (Supplementary Fig. S3C). These observations are consistent with a role for BRCAl in the recruitment of activated ATM to DNA breaks throughout the cell cycle, even at the very low levels of BRCA1 protein expressed during G1.

\section{Interelationships of NBS1 and BRCA1 foci and phosphorylation}

Although both NBS1 and BRCA1 are required for recruitment of activated ATM to the sites of double-strand breaks, the interdependencies of these two proteins in radiation responses required clarification. Consistent with a previous report (Wu et al. 2000), NBS1 protein formed foci after irradiation of cells lacking full-length BRCA1 with no further changes after BRCA1 complementation (Fig. 4A). Reciprocally, BRCA1 protein formed foci in cells lacking NBS1 (Fig. 4B). In contrast to the lack of interdependencies for IR-induced foci formation, phosphorylation of each of these proteins after IR was dependent on the other. IR-induced phosphorylation of NBS1 at Ser 343 was abrogated in BRCA1-deficient cells and was restored by expression of full-length BRCA1 (Fig. 4C). Reciprocally, IR-induced phosphorylation of BRCA1 was absent in cells lacking full-length NBS1 and was restored following complementation with full-length NBS1 (Fig. 4D). Thus, phosphorylation of these proteins correlated with the recruitment of activated ATM into foci after IR. These results are consistent with a model in which NBS1 and BRCA1 localize to the sites of double-strand breaks independently, but are both required for recruitment of phosphorylated ATM to the IR-induced foci. Absence of either protein causes a failure of recruitment of activated ATM to the doublestrand breaks, resulting in loss of phosphorylation of NBS1, BRCA1, and SMC1 at the focus.

Generation of Smc1 ${ }^{\text {S957AS966A }}$ phosphorylation mutant mouse cells

Cells lacking normal ATM, NBS1, or BRCA1 genes share several common features, including cell cycle checkpoint defects, radiosensitivity, and increased chromo- 
Kitagawa et al.

Figure 3. Influence of BRCA1 on IR-induced phosphorylation and localization of ATM. (A) HCC1937 (BRCA1-deficient) cells were transiently transfected with a human expression vector, carrying (BRCA1wt) or not carrying (vector) a wildtype BRCA1 gene. Following exposure to indicated doses of ionizing irradiation, total and phosphorylated ATM was assessed by immunoblot after immunoprecipitation, and total and phosphorylated SMC1 and total BRCA1 were assessed by immunoblot of whole-cell extracts. (B) Subcellular localization of BRCA1, phophorylated ATM, and H2AXy in BRCA1-deficient or -proficient cells. Cells were fixed $15 \mathrm{~min}$ after $0 \mathrm{~Gy}(\mathrm{IR}-)$ or $5 \mathrm{~Gy}(\mathrm{IR}+)$ of $\gamma$ irradiation, then labeled with antibodies or DAPI as indicated.

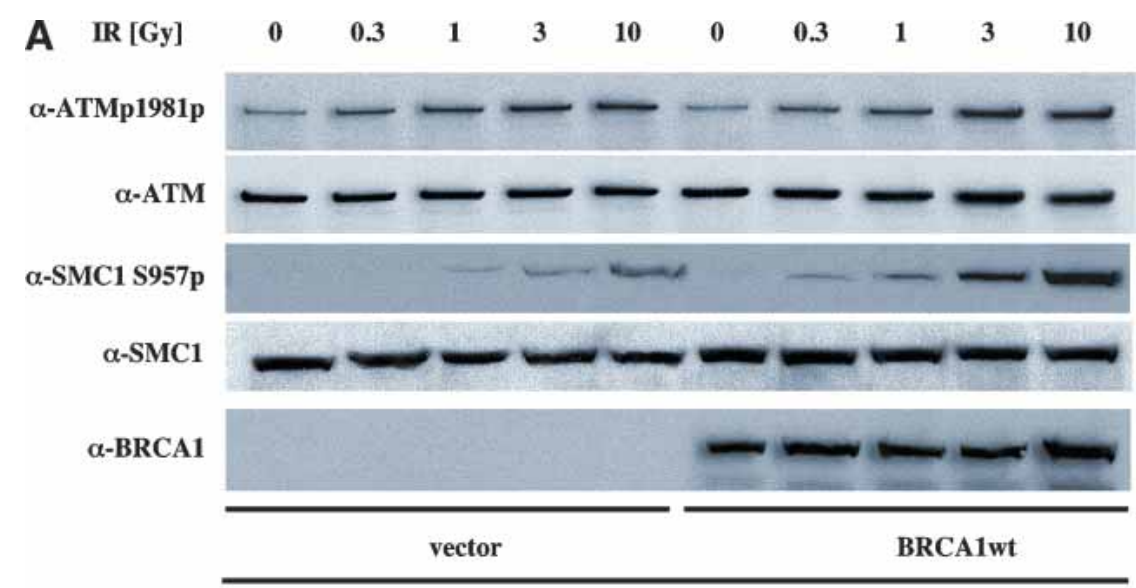

B

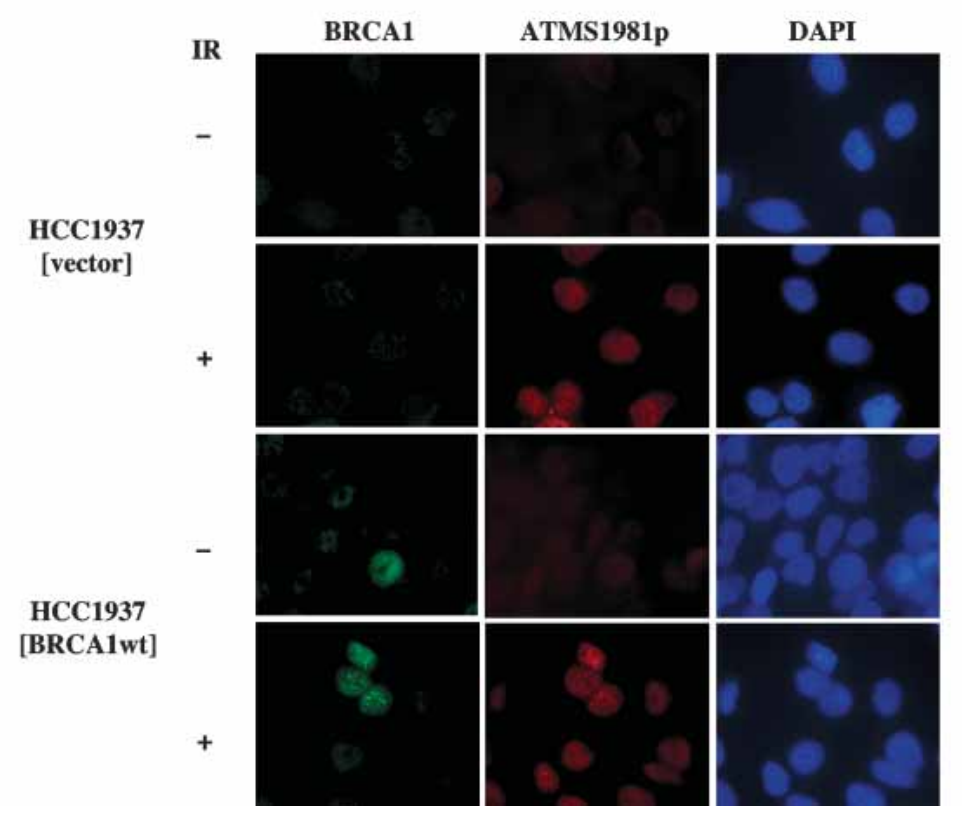

taining homologous integration of pSmc1KI-Neotk, then the Neo-tk cassette was removed by transiently expressing Cre recombinase. The targeted ES clone was microinjected into donor blastocysts, and chimeric males derived from the clone transmitted the targeted allele through the germ line when mated with C57BL/6 females.

Mouse skin fibroblast cells were cultured from 4week-old Smc1 ${ }^{\text {S957AS966A/- }}$ (Smc1 S957AS966A) $^{\text {mice and }}$ their $S \mathrm{mc1}^{+/-}\left(S \mathrm{Sc} \mathrm{1}^{W T}\right)$ siblings and mouse embryonic fibroblast cells (MEFs) were cultured from Smc1 ${ }^{\text {S957AS966A/- }}\left(\right.$ Smc1 $\left.{ }^{\text {S957AS966A }}\right)$ and wild-type $S m c 1^{+/-}\left(S m c 1^{W T}\right)$ embryos 13.5 d post coitum. Both $S m c 1^{\text {S957AS966A }}$ and Smc1 $1^{W T}$ MEFs continued to divide, could be continuously passaged, and spontaneously immortalized with extended passage in culture. Levels of SMC1 protein were not altered in the mutant cells (Fig. $5 \mathrm{~B})$, and cell cycle progression was unaffected, including progression through mitosis, in Smc1 $1^{\text {S957AS966A }}$ MEFs (data not shown). The absence of phosphorylation at Ser 


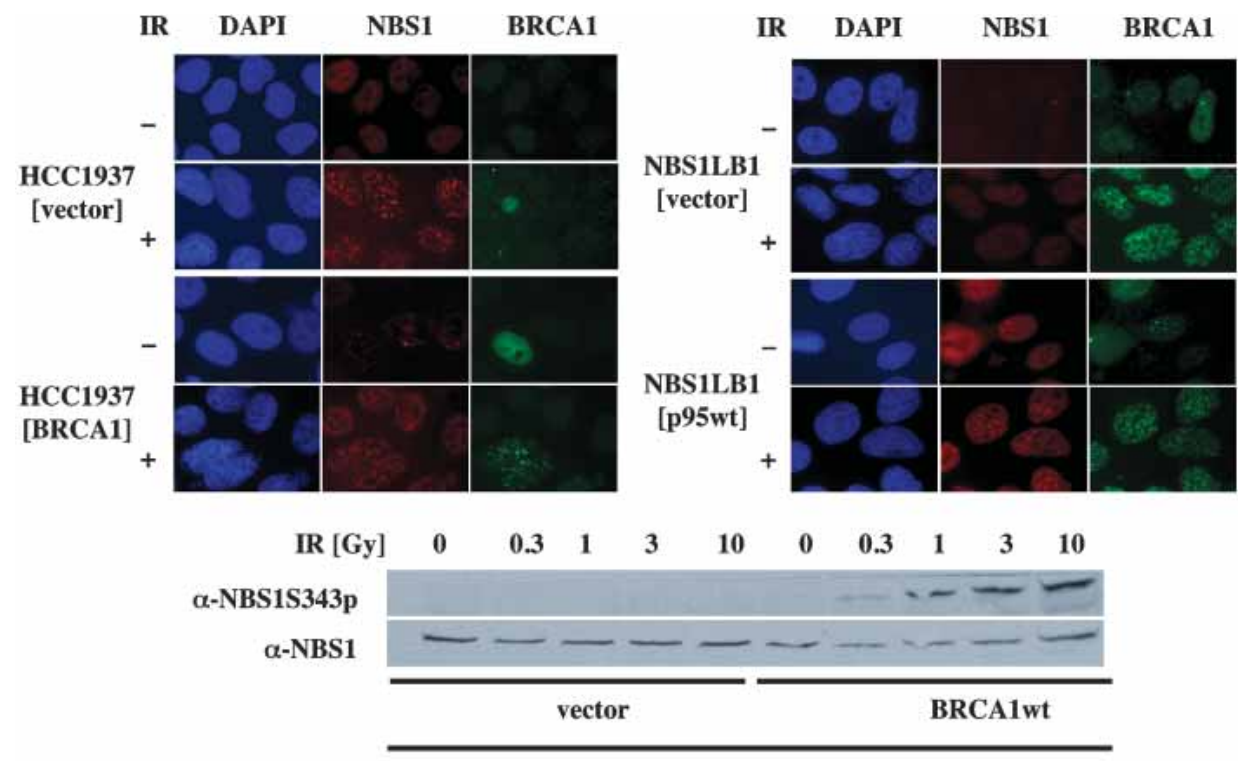

HCC1937

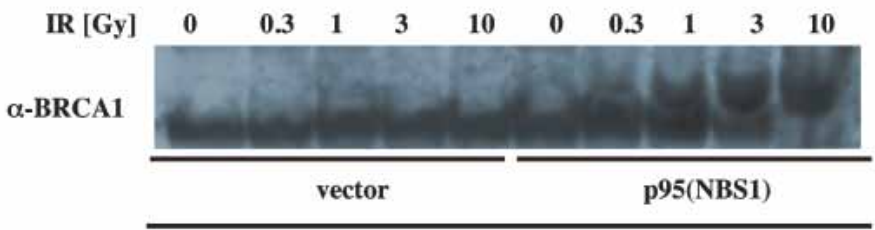

NBS1-LB1

Figure 4. Interdependencies of IR-induced foci formation and pbosphorylation of NBS1 and BRCA1. $(A, B)$ Subcellular localization of NBS1 and BRCA1 in HCC1937 (BRCA1-deficient) cells transfected with a transient expression vector carrying BRCA1 gene (BRCA1wt) or an empty vector (vector; A) and NBS1-LB1 (NBS1-deficient) cells stably transfected with a retrovirus vector carrying p95/Nbs1 gene (p95) or an empty vector (vec) were analyzed by immunofluorescence microscopy (B). Cells were fixed 15 min after 0 $\mathrm{Gy}(\mathrm{IR}-$ ) or $5 \mathrm{~Gy}(\mathrm{IR}+$ ) of $\gamma$ irradiation, then labeled with anti-NBS1 (shown in red) or anti-BRCA1 (shown in green). DNA was visualized by staining with DAPI (shown in blue). (C) HCC1937 (BRCA1-deficient) cells were transiently transfected with a human expression vector, pcDNA3 carrying (BRCA1wt) or not carrying (vector) wild-type BRCA1 gene. Following exposure to indicated doses of ionizing irradiation, cellular extracts were subjected to immunoblotting. Cell extracts were blotted with antibody to phosphorylated Ser 343 of NBS1, then reblotted with anti-NBS1 antibody. (D) Cellular extracts of NBS1-LB1 cells stably transfected with a retrovirus vector carrying $p 95 / N B S 1$ gene [p95(NBS1)] or an empty vector (vector) exposed to indicated doses of ionizing irradiation were separated on $5 \%$ Tris-acetate gel and blotted with anti-BRCA1 antibody.

957 and Ser 966 of SMC1 in Smc1 $9957 A S 966 A$ cells exposed to $10 \mathrm{~Gy}$ of irradiation was confirmed by immunoblotting and confirms the specificity of the new antiphospho-Ser 957 monoclonal antibody that was generated to recognize this modification in mouse and human cells (Fig. 5B).

Smc1 knock-in mutations do not affect phosphorylation or focus formation of other ATM substrates after IR

The phosphorylation of both ATM and p53 in Smc1 ${ }^{\text {S957AS966A }}$ MEFs after IR was indistinguishable from that observed in $S m c 1^{W T}$ MEFs, indicating that IRinduced activation of ATM kinase is not affected by SMC1 mutation (Fig. 5B). The IR-induced phosphorylation of NBS1 and BRCA1 proteins in the Smc1 mutant knock-in cells was also assessed. Because of differences in amino acid sequences surrounding the ATM phos- phorylation sites in NBS1 and BRCA1, the phospho-specific antibodies recognizing phosphorylated Ser 343 of human NBS1 or phosphorylated Ser 1387 or Ser 1423 of human BRCA1 do not recognize their murine corresponding sites. Although phosphorylation site-specific antibodies could not be used, IR-induced phosphorylation following cellular irradiation can be followed by altered mobility of both of these proteins in SDS-PAGE, with reversal of the shifts following treatment with protein phosphatase. IR-induced mobility shifts of murine NBS1 and BRCA1 proteins in Smc1 ${ }^{\text {S957AS966A }}$ cells were indistinguishable from those seen in wild-type cells (Fig. 5C).

A potential role for SMC1 phosphorylation in the formation of IR-induced foci was examined by immunofluorescence. As observed in the human cells (Fig. 2), SMC1 protein in murine fibroblasts localizes in foci after DNA damage. The anti-S957-P monoclonal antibody localized to foci within 30 min of irradiation in cells con- 
Kitagawa et al.

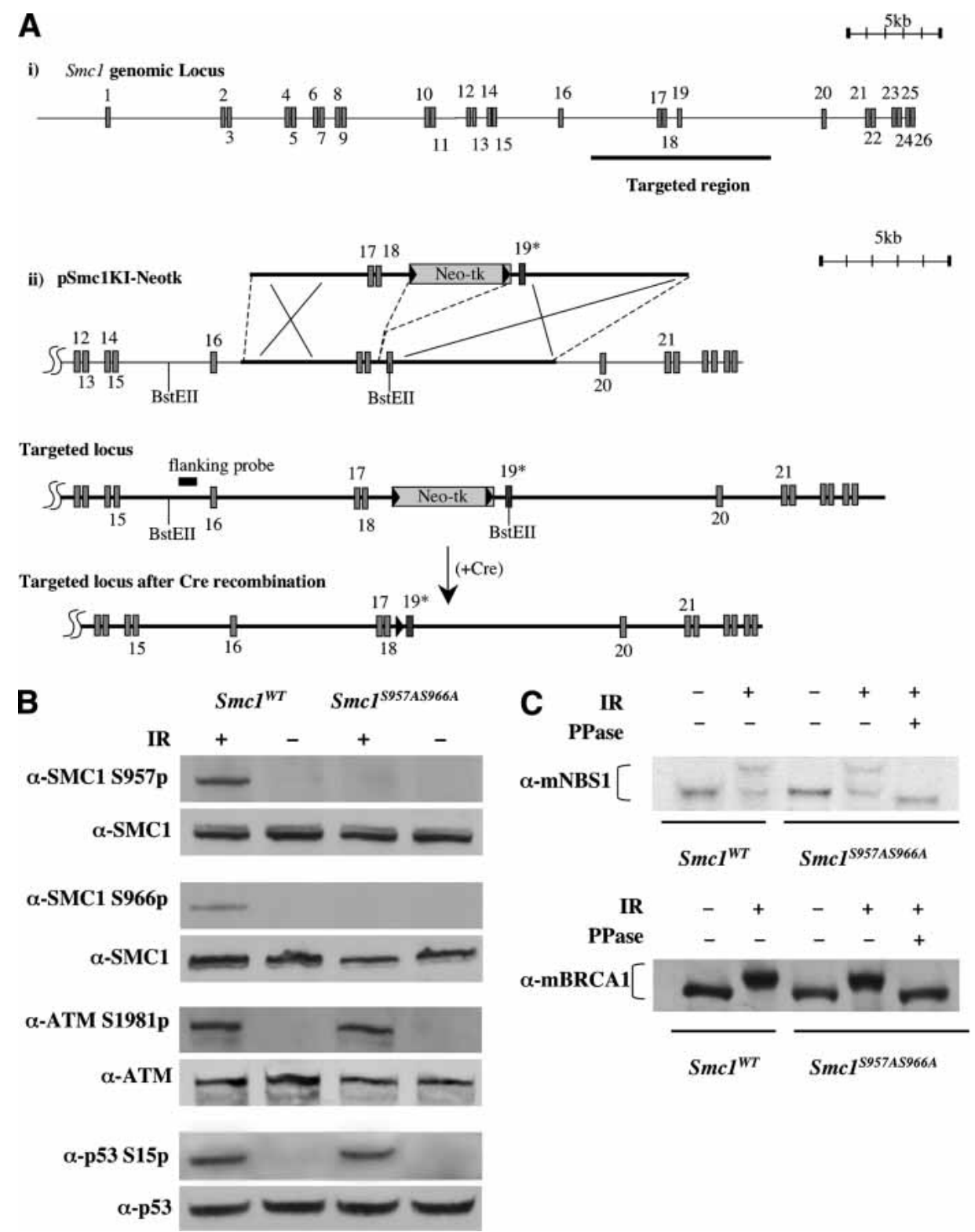

Figure 5. Targeted modification of the mouse $S m c 1$ gene and effects on radiation responses. (A) Schematic of Smc1 knock-in procedure. (panel i) Genomic structure of the mouse Smc1 gene on chromosome X. The whole genomic Smc1 gene consists of 26 exons shown as boxes. Targeted region into which to insert the knock-in vector is shown as a thick bar. (panel ii) Targeting construct of the knock-in vector, pSmc1KI-Neotk, targeted locus, and targeted locus following cre-mediated recombination. Neomycin resistance and thymidine kinase genes (Neo-tk) flanked by loxP sites (shown as black triangles) are inserted into an intron between exon 18 and 19. In pSmc1KI-Neotk, two nucleotide exchanges to change serine to alanine at amino acid positions 957 and 966 are made in exon 19 (shown as a dark box labeled as $19^{\star}$ ). Homologus recombination of the pSmc1KI-Neotk is depicted by the large " $\times^{\prime \prime}$ s. Positions of the flanking probe for genotyping and BstEII sites are indicated. (B) Wild-type $\left(S m c 1^{W T}\right)$ or Smc1 ${ }^{\text {S957AS966A }}$ immortalized mouse fibroblast cells were exposed to $0 \mathrm{~Gy}$ (IR-) or $10 \mathrm{~Gy}(\mathrm{IR}+)$ of ionizing irradiation and cellular extracts were prepared $30 \mathrm{~min}$ later. Whole-cell lysates were subjected to immunoblotting with antibodies as indicated. $(C)$ Thirty minutes after exposure to $0(-)$ or $10(+) \mathrm{Gy}$ of ionizing irradiation (IR), whole-cell lysates were prepared from wild-type or mutant knock-in fibroblasts were immunoblotted with anti-mouse NBS1 or BRCA1 antibodies. Duplicate samples of cell lysates from irradiated knock-in cells were treated with protein phosphatase (PPase+) prior to electrophoresis.

taining wild-type SMC1, and no immunofluorescence was apparent in the knock-in cells (Fig. 6). In wild-type cells, foci of phospho-ATM, H2AX $\gamma$, NBS1, 53BP1, phosphorylated CHK2 on Thr 68, and BRCA1 were all appar- ent after IR, and all colocalized with the SMC1 foci (Fig. 6). In the SMC1 knock-in cells, although no SMC1 foci were visible, focus formation with all of the other proteins was indistinguishable from that seen in wild-type 
A

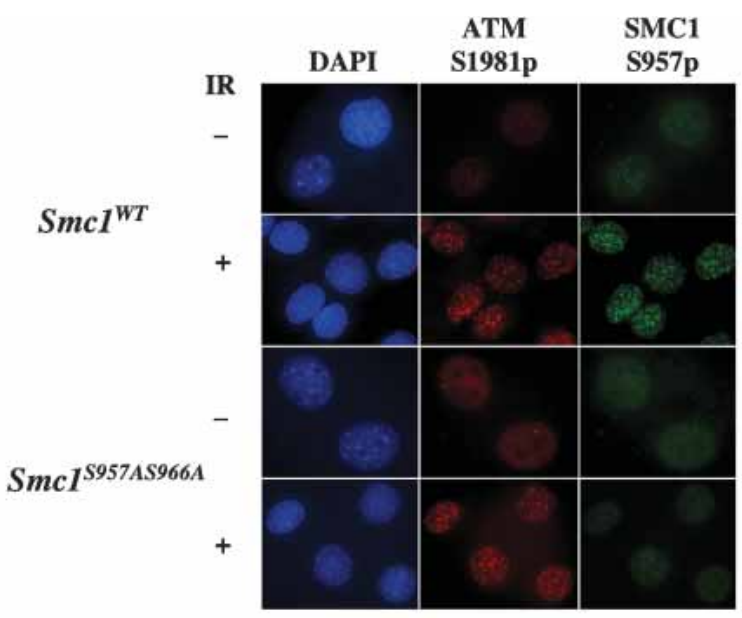

B

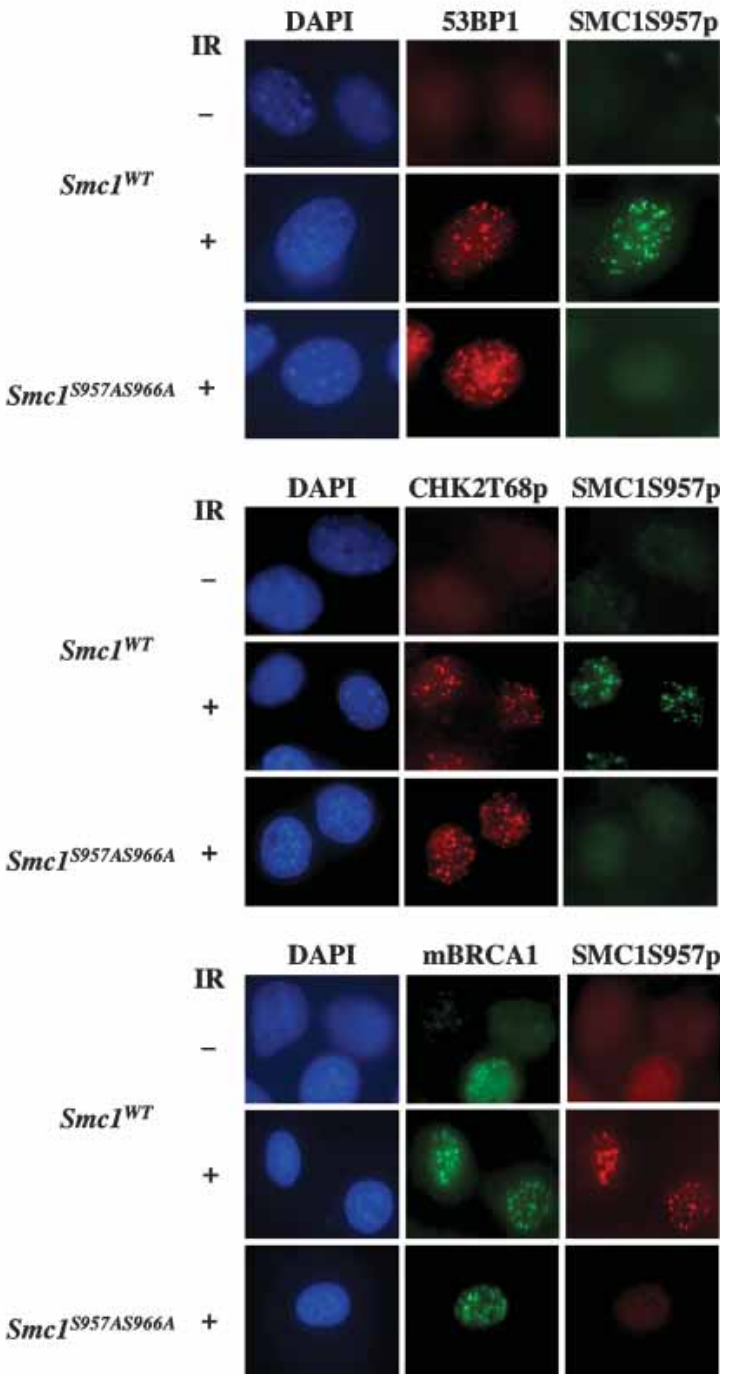

Figure 6. SMC1 phosphorylation is not required for IR-induced formation of foci containing phospho-ATM, H2AX $\gamma$, NBS1, 53BP1, phosphorylated CHK2, or BRCA1. Wild-type $\left(S m c 1^{W T}\right)$ or $S m c 1$ phosphorylation mutant knock-in $\left(S m c 1^{S 957 A S 966 A}\right)$ fibroblast cells were fixed with $4 \%$ paraformaldehyde 30 min after $0 \mathrm{~Gy} \mathrm{(-)} 10 \mathrm{~Gy}(+)$ of ionizing irradiation (IR), then subjected to immunofluorescence microscopy. (A) Staining with antibodies recognizing phosphorylated ATM or SMC1. (B) Staining with antibodies recognizing $\mathrm{H} 2 \mathrm{AX} \gamma$, NBS1, 53BP1, phosphorylated CHK2, BRCA1, and phosphorylated SMC1. For costaining of phosphorylated SMC1 (red) with BRCA1 (green), rabbit polyclonal anti-Ser957p antibody was used. 
cells. Thus, organization of IR-induced foci formation at the sites of DNA double-strand breaks was not affected by loss of IR-induced phosphorylation of SMC1.

Despite normal formation of foci, Smc1 mutant knock-in cells have abnormal responses to DNA damage

Previous studies demonstrated that overexpression of SMC1 protein mutated at the ATM phosphorylation sites in cells with normal endogenous SMC1genes results in S-phase checkpoint abnormalities and decreased cell survival after IR (Kim et al. 2002; Yazdi et al. 2002). Consistent with these observations, Smc1 $1^{\text {S957AS966A }}$ MEF cells exhibited a significant defect in the IR-induced S-phase checkpoint (Fig. 7A) and decreased cell survival following exposure to either IR (Fig. 7B) or the alkylating agent, methylmethanesulfonate (MMS; Fig. 7C). The magnitude of the S-phase checkpoint defect and radiosensitivity are indistinguishable from the defects seen in ATM-null MEF cells (data not shown). Because ATM-null cells are not hypersensitive to MMS, this suggests a critical role for SMC1 phosphorylation in other damage-response pathways. We recently observed that SMC1 phosphorylation after UV irradiation is dependent on ATR (Garg et al. 2004), suggesting an important role for SMC1 phosphorylation in the ATR pathway as well.

A pathognomonic feature of cells lacking ATM is the persistence of chromosomal aberrations for relatively long periods of time after IR, presumably reflecting a defect in some aspect of chromosomal repair (Pandita and Hittelman 1992; Morgan et al. 1997). Thus, the induction and disappearance of chromosome aberrations following IR was examined in very early passage $(<4)$ Smc1 $1^{\text {S957AS966A }}$ MEF cells. Although chromosomal aberrations after 1 Gy IR were easily detectable in both $S m c 1^{W T}$ and Smc1 $1^{\text {S957AS966A }}$ MEF cells, the number of chromosome aberrations per cell decreased much more rapidly after IR in $S m c 1^{W T}$ cells than in Smc1 $1^{\text {S957AS966A }}$ cells (Fig. 7D). This slow disappearance of IR-induced chromosomal breaks is indistinguishable from what we have previously observed in human cells lacking ATM (Morgan et al. 1997; Smilenov et al. 1997). Thus, despite normal phosphorylation and focus formation of ATM, NBS1, and BRCA1 proteins, Smc1 $1^{\text {S957AS966A }}$ cells exhibit S-phase checkpoint abnormalities, decreased cell survival after DNA damage, and decreased disappearance of chromosomal breaks after IR. These data underscore the critical downstream role of SMC1 protein in determining chromosomal integrity and radiosensitivity in this mammalian DNA-damage-response pathway.

\section{Discussion}

Eukaryotic cells have evolved elaborate mechanisms to deal with damage to their DNA, presumably to decrease the frequency of gene mutations and to enhance cellular survival when appropriate. Temporary cessation of cell cycle progression and the ability to repair DNA breaks or altered DNA bases are among the processes used by cells to deal with DNA damage. The importance of gene products involved in these damage-response processes in reducing human cancer risk is demonstrated by the markedly increased risks of cancer observed in individuals bearing germ-line mutations in one of these genes. Mutations in the ATM, p53, NBS1, BRCA1, FANCD2, and $C H K 2$ genes have all been found in familial cancer syndromes and all play important roles in cellular responses to DNA damage. These proteins interact with each other in signal-transduction pathways initiated by DNA damage and p53, NBS1, BRCA1, FANCD2, and CHK2 are all substrates of the ATM kinase (Banin et al. 1998; Canman et al. 1998; Cortez et al. 1999; Lim et al. 2000; Matsuoka et al. 2000; Xu et al. 2001; Taniguchi et al. 2002). Cells lacking ATM, NBS1, or BRCA1 all exhibit decreased cell survival and increased chromosomal instability following DNA breakage. However, the exact mechanisms by which these proteins influence these particular cellular endpoints have not been clarified. We present data here that implicate SMC1 as a critical target downstream of all three of these proteins that contributes to these phenotypic abnormalities.

SMC1 protein plays critical roles in mitotic progression and is an essential cellular protein (Michaelis et al. 1997). A novel cellular role for SMC1 was identified when it was shown to be a target of the ATM kinase in irradiated cells (Kim et al. 2002; Yazdi et al. 2002). Overexpression of SMC1 protein mutated at the ATM phosphorylation sites negatively affected transient S-phase arrest and cell survival following IR, suggesting a role for SMC1 phosphorylation in these two DNA-damage responses. To formally demonstrate functional roles for SMC1 protein in these processes, we generated ES cells, mice, and fibroblasts with both of these phosphorylation sites mutated. Cells lacking these phosphorylation sites exhibited a defect in the S-phase checkpoint, decreased cell survival, and increased chromosomal breakage after DNA damage, thus confirming the functional roles for SMC1 phosphorylation after DNA damage.

Evaluations of the interdependencies of phosphorylation of ATM, NBS1, BRCA1, and SMC1 and the doseresponsiveness of each of these phosphorylation events provided important mechanistic insights into the order of events in this signaling pathway. Although the levels of phosphorylation of NBS1, H2AX, and SMC1 continued to increase with increasing doses of IR (at least up to 30 Gyl, phosphorylation of ATM and p53 at early time points (prior to p53 induction) becomes maximal at very low doses of IR $(<1-3 \mathrm{~Gy})$. These results suggested a correlation between the number of DNA strand breaks and the phosphorylation of NBS1, H2AX, and SMC1, but no such correlation between DNA breaks and phosphorylation of ATM or p53. This observation was consistent with our previous suggestion that the initial activation of ATM and phosphorylation of p53 does not occur via direct binding of ATM to DNA-strand breaks (Bakkenist and Kastan 2003). The activation of ATM by agents that alter chromatin structure without introducing detectable DNA strand breaks further supported this concept. In this setting of ATM activation in the absence of DNA 
A
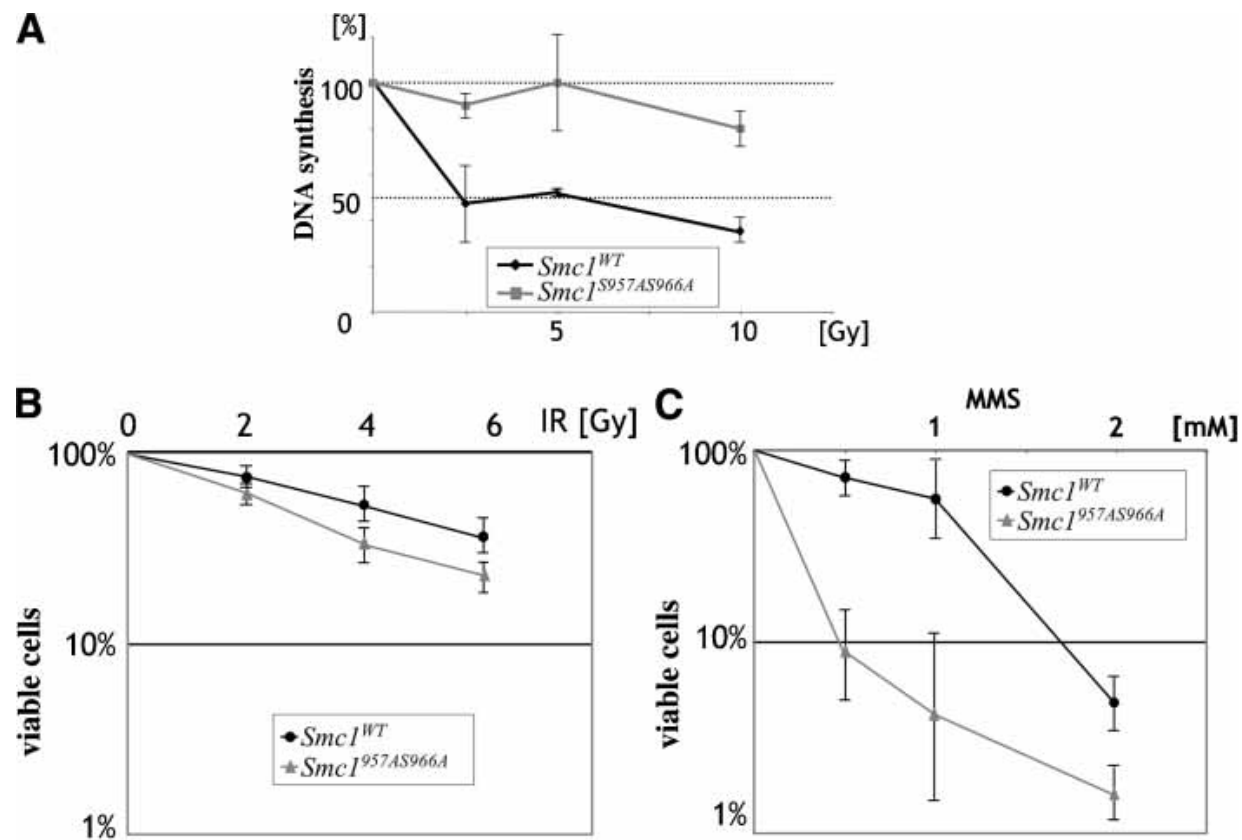

D

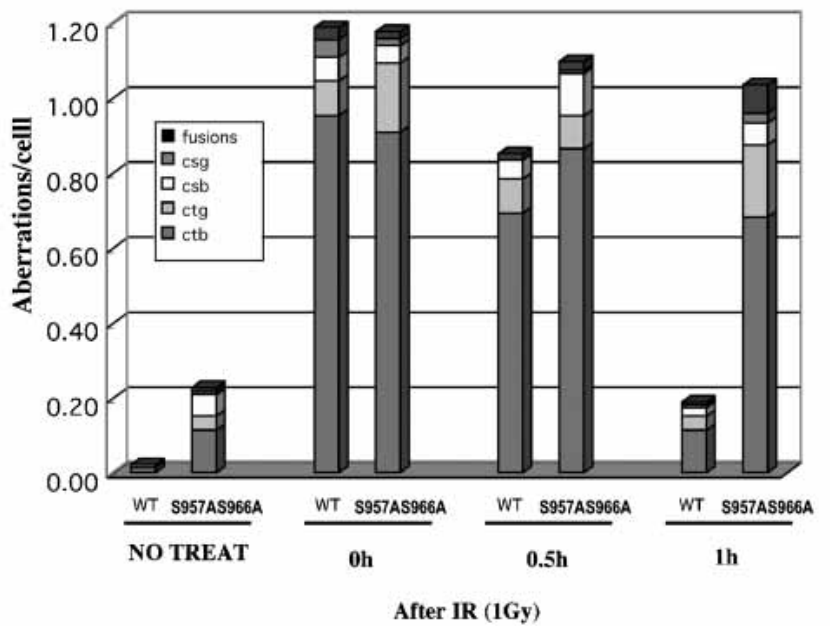

Figure 7. Radiation response abnormalities in Smc1 mutant knock-in cells. (A) Defect in the S-phase checkpoint. MEFs derived from wild-type $\left(S m c 1^{W T}\right)$ or $S m c 1^{S 957 A S 966 A}$ embryos were assessed for inhibition of DNA synthesis 30 min after exposure to indicated doses of IR. Error bars are average of triplicate samples. $(B)$ Increased sensitivity to IR. Wild-type or knock-in immortalized mouse fibroblast cells were plated in 6-well culture dishes and irradiated with the indicated doses of ionizing radiation (IR). Cell viability was assessed $72 \mathrm{~h}$ after treatment, and is plotted as the percent viable cells relative to results for untreated control cultures. Each point represents the mean of three samples, with error-bars showing standard deviation. The radiosensitivity of Smc1 mutant knock-in fibroblasts was indistinguishable from that seen in ATM-null murine fibroblasts (data not shown). $(C)$ Increased sensitivity to alkylating agents. Wild-type or Smc1 mutant knock-in immortalized mouse fibroblast cells were plated in 6-well culture dishes, and treated with methylmethane sulfonate (MMS) for $1 \mathrm{~h}$. Cell viability was assessed $72 \mathrm{~h}$ after treatment, and is plotted as the percent viable cells relative to results for untreated control cultures. Each point represents the mean of three samples, with error-bars showing standard deviation. (D) Defect in chromosomal repair after IR. MEFs derived from wild-type or knock-in embryos were irradiated with 1 Gy of ionizing irradiation (IR), then treated with colcemid at indicated times after irradiation. Chromosome aberrations were scored in 100 metaphase spreads of each sample and numbers of chromosome gaps (csg), chromosome breaks (csb), chromatid gaps (ctg), and cromatid breaks (ctb) per cell were charted.

breaks, p53 phosphorylation is detected, but no phosphorylation of H2AX (Bakkenist and Kastan 2003), SMC1, or NBS1 (Fig. 1B) is evident, again suggesting that the phosphorylation of the latter group of ATM substrates is dependent on DNA breaks.

As previously reported (Kim et al. 2002; Yazdi et al.
2002), the phosphorylation of SMC1 by ATM after IR is dependent on NBS1 and BRCA1 (Fig. 2). Examination of subcellular localization of these proteins by immunofluorescence after IR was informative in explaining these dependencies. NBS1, BRCA1, and SMC1 all normally localize to foci after cellular irradiation (Figs. 2, 3) and 
antibodies to phosphorylated ATM also reveal focus formation within several minutes after IR (Bakkenist and Kastan 2003; Fig. 2). IR-induced autophosphorylation of ATM was evident by both immunoblot and immunofluorescence in cells lacking NBS1 or BRCA1. However, in the absence of functional NBS1 or BRCA1 proteins, the activated/phosphorylated ATM protein fails to localize to foci after IR. Thus, NBS1 and BRCA1 are not required for the initial activation of ATM, but rather appear to play an important role in recruiting ATM that is already activated to the sites of DNA breaks, where it can then phosphorylate substrates, including NBS1, BRCA1, and SMC1. Our subsequent results implicated the phosphorylation of SMC1 at the break as the ATM target required for optimal cell survival and chromosomal repair.

Recent publications have suggested that the MRE11/ NBS1 (M/R/N) complex is "upstream" or "required" for the activation of ATM (Carson et al. 2003; Mochan et al. 2003; Uziel et al. 2003). Figure 2 unequivocally demonstrates that ATM can be activated in cells lacking fulllength NBS1. Thus, functional NBS1 is not absolutely required for the activation of ATM. Cells lacking fulllength NBS1 do exhibit a quantitative decrease in the amount of ATM phosphorylation after low doses of IR, but no significant abnormality was evident after higher doses of IR. The more impressive influence that NBS1 appears to have on ATM activity in the cell is the marked difference in subcellular localization of activated ATM after DNA damage, with cells lacking NBS1 failing to recruit activated ATM to foci. The quantitative decrease seen in ATM phosphorylation by immunoblot after low-dose IR in cells lacking NBS1 may be simply related to this mislocalization. For example, it is conceivable that activated, phosphorylated ATM has a longer half-life at the sites of DNA breaks than it does in the nucleoplasm, and thus, a failure to recruit ATM to foci in NBS1-deficient cells could result in lower cellular levels of phosphorylated ATM. Alternatively, once activation of ATM is initiated, the signal could be amplified such that activated ATM continues to activate other ATM molecules in the cell. If the amplification is dependent on NBS1, the quantitative differences observed in the NBS cells might be the result. Finally, the endonuclease activity of MRE11 in the M/R/N complex may process the DNA strand break, and in doing so, enhance the chromatin structure change that activates ATM (Mirzoeva and Petrini 2003). This might be consistent with the observation that higher doses of IR could overcome the quantitative effects of NBS1 dysfunction on ATM activation. It is also worth noting that MRE11 and NBS1 could play different roles in activating or recruiting ATM.

Regardless, the conclusion that the $M / R / N$ complex is absolutely required for ATM activation is not consistent with our results, nor is it an accurate description of the published data in the literature. Despite the stated conclusions, previously published data (Carson et al. 2003; Mochan et al. 2003; Uziel et al. 2003) are more consistent with the conclusion drawn here and recently else- where (Horejsi et al. 2004) that the deficit in ATM activation in cells lacking NBS1 or MRE11 is quantitative, not absolute. In addition, many of the experimental results in these studies that were used to support the concept that $\mathrm{M} / \mathrm{R} / \mathrm{N}$ is important for ATM activation actually assessed the phosphorylation of ATM substrates rather than measuring ATM activation directly. As our data demonstrates, the process of activating ATM is distinct from the process of phosphorylation of ATM substrates, with the latter requiring the ability of the activated ATM to find and phosphorylate its substrates in the cell. For example, we observe activation of ATM in cells lacking full-length NBS1 or BRCA1, although phosphorylation of ATM substrates, like SMC1, is significantly defective. Thus, ATM "activation" and ATM "activity" are distinct cellular readouts, and substrate phosphorylation is an incomplete surrogate marker for ATM activation.

Two recent observations further support this model. First, a mouse containing mutant Mre11 alleles has a normal IR-induced G1 checkpoint (Theunissen et al. 2003). Because the G1 checkpoint requires normal p53 induction after IR, which requires ATM activity, this observation suggests the presence of ATM activation in the absence of normal MRE11. Second, the M/R/N complex was recently shown to be required for ATM phosphorylation of substrates in vitro (Lee and Paull 2004). Although the title of this paper suggested that $\mathrm{M} / \mathrm{R} / \mathrm{N}$ was required for ATM activation, the activation of ATM was not directly measured. Rather, the ability of ATM to phosphorylate substrates was measured. Both the data in the Lee and Paull (2004) study and the data contained herein suggest that $\mathrm{M} / \mathrm{R} / \mathrm{N}$ is required to recruit $\mathrm{ATM}$ to the DNA breaks, and that this recruitment is required for ATM to phosphorylate substrates like NBS1, BRCA1, and SMC1. Thus, in the model described below we suggest that initiation of ATM activation is not absolutely dependent on NBS1, and conversely, that localization of the NBS1 complex at DNA-strand breaks is not dependent on ATM (Mirzoeva and Petrini 2001). Rather, these occur initially as independent events and activated ATM and NBS1 protein subsequently come together and interact, apparently at the site of the DNA break and with the NBS1 protein playing a critical role in recruiting ATM to this site.

In contrast to ATM activation, the dependence of SMC1 phosphorylation on the presence of functional NBS1 and BRCA1 places both of these proteins upstream of SMC1 phosphorylation. Because phosphorylated SMC1 colocalizes in foci with phospho-ATM and NBS1, it appears that SMC1 is phosphorylated by ATM at the site of DNA breaks. The dependence of SMC1 phosphorylation on NBS1 and BRCA1 appears to result from the role of these two proteins in recruiting activated ATM to the DNA breaks. This is an ordered dependence, because foci of NBS1, BRCA1, phosphorylated ATM, and other ATM substrates all appear to occur normally in the Smc1 mutant knock-in cells. As these knock-in cells exhibit an S-phase checkpoint defect, chromosomal instability and hypersensitivity to DNA damage that are 
similar to that seen in cells lacking ATM, NBS1 or BRCA1, SMC1 appears to be a critical downstream target for these phenotypic abnormalities.

Taken together, we propose a model in which an ordered dependency of events occurs through the initiation of the DNA-damage-induced signaling pathway as shown in Figure 8. ATM is autophosphorylated by a signal generated by a structural change of chromatin that can be caused by introduction of double-strand breaks into chromosomal DNA or by other processes. If DNA double-strand breaks are present, various proteins are then recruited to the sites of the breaks in a hierarchical and ordered manner. H2AX is phosphorylated and NBS1 and BRCA1 are recruited quickly into the focus complex. ATM, which is already activated, is then recruited into the focus complex in a process dependent on NBS1 and BRCA1. This recruitment of activated ATM to the break provides access of ATM to break-associated targets and allows efficient phosphorylation of these targets. The ob- servations that NBS1 and BRCA1 localize to foci independent of each other, whereas their phosphorylation is dependent on each other (because of the requirement for ATM recruitment), are all consistent with this model.

SMC1 appears to be a critical substrate for chromosomal repair and cell survival. This process could be analogous to a process in budding yeast, where binding of Xrs2p (an NBS1 ortholog) to Tellp (a member of the ATM superfamily) is required for recruitment of Tellp into the double-strand breaks (Nakada et al. 2003). Although the MRE11-binding domain of NBS1 is likely required for this interaction, as it is required for $\mathrm{CHK} 2$ and SMC1 phosphorylation (Lee et al. 2003; Horejsi et al. 2004), it is not clear whether NBS1 recruits ATM into the double-strand breaks by directly binding to ATM. If ATM is activated, but there are no DNA breaks (e.g., after chloroquine), or if ATM is not recruited to the breaks (e.g., in NBS1-deficient cells after IR), then nucleoplasmic substrates like p53 get phosphorylated, but

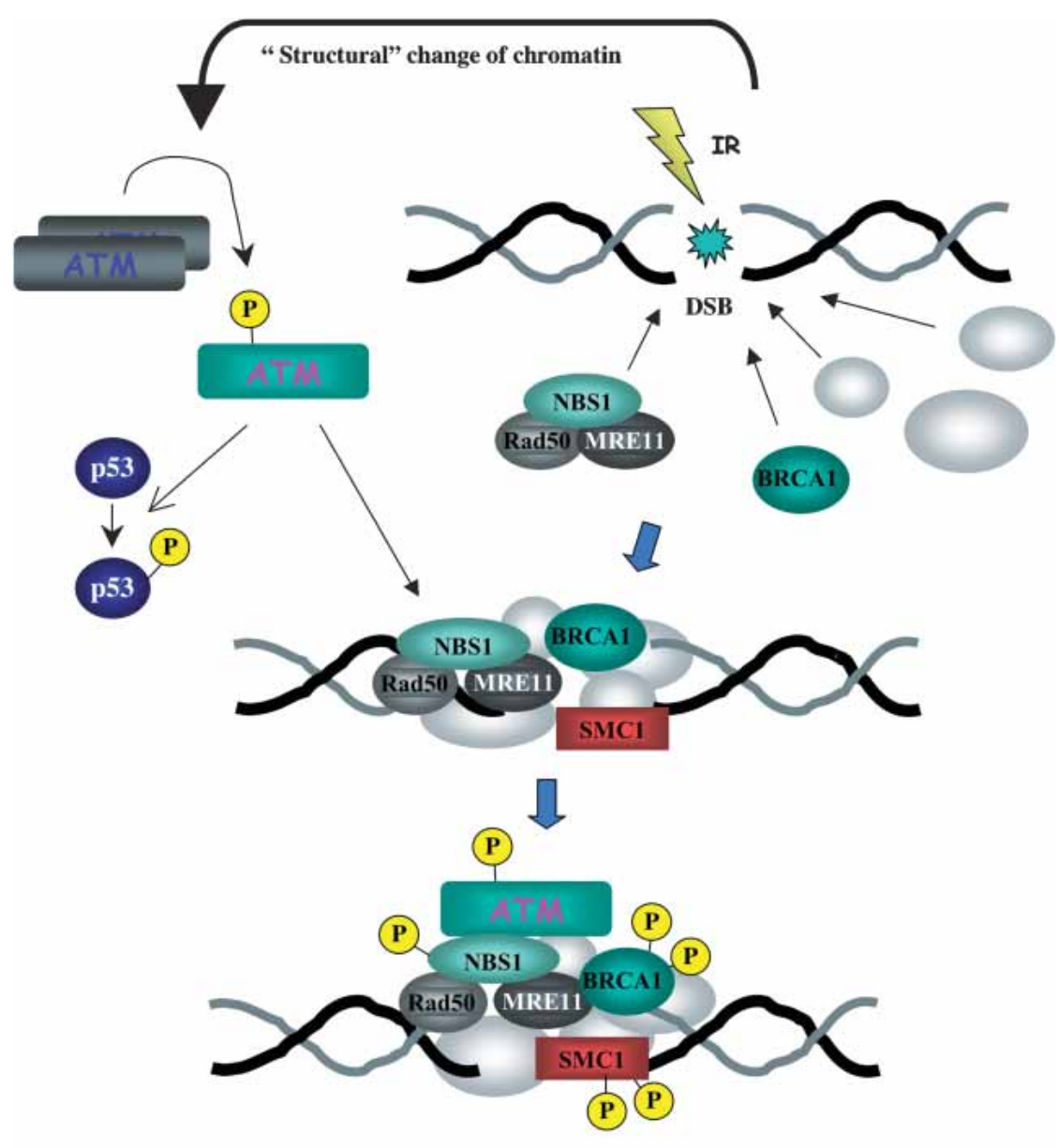

DNA repair

(Modulation of radiosensitivity )

Cell Cycle checkpoint
Figure 8. Proposed model for an IR-induced signaling pathway. Chromatin structure changes caused by DNA breakage or other mechanisms leads to intermolecular autophosphorylation of ATM dimers, resulting in release of phosphorylated and active ATM monomers. If DNAstrand breaks are present, several proteins, including NBS1 and BRCA1, are recruited to the sites of the breaks independent of the ATM activation process. After activation, monomeric ATM can phosphorylate nucleoplasmic substrates, like p53, and if NBS1 and BRCA1 have localized to DNA breaks, activated ATM is recruited to the break. At the DNA break, activated ATM can phosphorylate substrates, including SMC1. The phosphorylation of SMC1 reduces chromosomal breakage and enhances cell survival. 
substrates at the breaks, like SMC1, do not get phosphorylated.

Identification of SMC1 phosphorylation as a critical event in this pathway affecting cell survival and chromosomal breakage after IR provides an important focus for future studies. Because we have previously shown that loss of cell cycle checkpoints by themselves do not result in decreased cell survival after DNA damage (Slichenmyer et al. 1993; Xu et al. 2001, 2002), it seems likely that $\mathrm{SMC1}$ phosphorylation is affecting some sort of DNA or chromosomal repair pathway. SMC1 has been identified in two distinct protein complexes, cohesin and RC-1. RC-1 has been suggested to have a DNA recombination activity (Jessberger et al. 1993, 1996; Stursberg et al. 1999|, and cohesin proteins in budding yeast have been implicated in postreplicative double-strand break repair (Sjogren and Nasmyth 2001). Because SMC1 phosphorylation does not appear to measurably affect cohesin function, it is reasonable to speculate that phosphorylation of SMC1 may recruit novel repair proteins to the sites of double-strand breaks. Identification of proteins that specifically interact with phosphorylated SMC1 now becomes an important goal of future experiments.

\section{Materials and methods}

\section{Cell culture}

The 1070SK primary human foreskin fibloblasts (HFFs; less than passage 20; American Type Culture Collection [ATCC]) and NBS-ILB1, an SV-40 transformed NBS fibroblast cell line that had been stably transfected with retroviral vectors carrying various constructs of Nbs1 genes (Lim et al. 2000; Lee et al. 2003), were cultured in DMEM supplemented with 10\% FBS. HCC1937 (BRCA1-mutated) tumor cells derived from a human ductal carcinoma was cultured in VitaCell (RPMI 1640 with 2 $\mathrm{mM}$ L-glutamine adjusted to contain $1.5 \mathrm{~g} / \mathrm{L}$ sodium bicarbonate, $4.5 \mathrm{~g} / \mathrm{L}$ glucose, $10 \mathrm{mM}$ HEPES, and $1.0 \mathrm{mM}$ sodium pyruvate, $90 \%$; ATCC) supplemented with $10 \%$ FBS. Mouse embryonic fibroblast (MEF) cells or mouse skin fibroblast cells were established as described below and cultured in MEF medium (DMEM supplemented with $2 \mathrm{mM}$ L-glutamine, 1\% nonessential amino acid [GIBCO-BRL], 10\% FBS). W9.5 mouse embryonic stem (ES) cells were cultured on feeder cells (MEF cells irradiated with $30 \mathrm{~Gy}$ of IR prior to seeding of ES cells) in ES medium (DMEM supplemented with $2 \mathrm{mM}$ L-glutamine, 1\% nonessential amino acid [GIBCO-BRL], $10 \mathrm{mM}$ HEPES, 0.1\% $\beta$-mercaptoethanol, 10\% FBS [certificated for ES cell culture]). All cell lines were grown at $37^{\circ} \mathrm{C}$ in a humidified atmosphere containing $5 \% \mathrm{CO}_{2}$. Ionizing radiation from a ${ }^{137} \mathrm{Cs}$ source was delivered at a rate of $\sim 120 \mathrm{cGy} / \mathrm{min}$. Chloroquine treatment was performed as previously described (Bakkenist and Kastan 2003). Transient transfections of cells were performed by using lipofectamine2000 (Invitrogen).

\section{Antibodies and Western blot detection}

Cell extracts were prepared in TNG buffer $(50 \mathrm{mM}$ Tris- $\mathrm{HCl}$ at $\mathrm{pH} 7.5,200 \mathrm{mM} \mathrm{NaCl}, 10 \mathrm{mM} \beta$-glycerophosphate, 1\% Tween $20,0.5 \%$ NP-40, $1 \times$ proteinase inhibitor cocktail from Roche) or RIPA buffer (200 mM NaCl, $10 \mathrm{mM}$ Tris at $\mathrm{pH} 7.5,0.1 \%$ SDS, $1.0 \%$ Triton X-100, $1 \%$ Deoxycholate, 5 mM EDTA, $1 \times$ proteinase inhibitor cocktail from Roche). To prepare cell extract containing H2AX proteins, cells were lysed in acid extraction buffer
(10 mM HEPES at $\mathrm{pH} 7.9,1.5 \mathrm{mM} \mathrm{MgCl}_{2}, 10 \mathrm{mM} \mathrm{KCl}, 0.2 \mathrm{M}$ $\mathrm{HCl}$ ), and cell extracts were dialyzed against $0.1 \mathrm{M}$ acetic acid for $1 \mathrm{~h}$ and $\mathrm{H}_{2} \mathrm{O}$ for $3 \mathrm{~h}$. Western blotting was performed with anti-ATM MAT3 (a gift of Y. Shiloh, Tel Aviv University, Ramat Aviv, Tel Aviv, Israel), anti-ATMS1981p-specific antibodies (Bakkenist and Kastan 2003), anti-NBS1 (Novus), antiNBS1S343p-specific antibody (Lim et al. 2000), anti-SMC1 (Kim et al. 2002), anti-BRCA1 (Ab-1; Oncogene), anti-H2AXS139pspecific antibody (JBW301; Upstate), anti-p53 (DO-1; Oncogene), and anti-p53S15p (Cell Signaling). Anti-SMC1S957p-specific antibodies were purified from tissue-culture supernatant of hybridoma cell line 5D11G5, which had been generated using the KLH-conjugated phosphopeptides SQEEGS[PO ${ }_{3}$ SQGEDS as an antigen (Zymed). In some cases, ATM proteins were immunoprecipitated with anti-ATM (D16.11; Alligood et al. 2000).

\section{Immunofluorescence microscopy}

Cells grown on glass slides were fixed with $4 \%$ paraformaldehyde in PBS for $30 \mathrm{~min}$ at room temperature, permeabilized with $0.5 \%$ Triton X-100 in PBS for 10 min at room temperature, then blocked with $10 \%$ skim milk in PBS containing $0.1 \%$ goat serum (Jackson Immunoresearch lab) for $30 \mathrm{~min}$ at room temperature. Cells were incubated with primary antibodies for $12 \mathrm{~h}$ at $4^{\circ} \mathrm{C}$ and with secondary antibodies (Alexa Fluor 546 goat anti-rabbit IgG or donkey anti-goat IgG and Alexa Fluor 488 goat anti-mouse IgG at 1:500 [molecular probe]) and DAPI (1 $\mu \mathrm{g} / \mathrm{mL})$ in PBS with $10 \%$ skim milk for $3 \mathrm{~h}$ at room temperature. Primary antibodies used for immunostaining were antiH2AXS139p-specific antibody (JBW301; Upstate) at 1:400, antiSMC1S957p-specific antibodies, anti-ATMS1981p-specific antibodies (Bakkenist and Kastan 2003) at 1:100, anti-human NBS1 (Novus) at 1:400, anti-human BRCA1 (Ab-1; Oncogene) at 1: 500, anti-mouse NBS1 (Chen et al. 2000) at 1:1000, anti-mouse BRCA1 (Ganesan et al. 2002) at 1:10, anti-CHK2T68p-specific antibody (Cell signaling) at 1: 200, and anti-53BP1 (Santa Cruz) at 1: 400. Microscopy images were captured by using Spot basic software. The specificity of the anti-ATMS1981p antibody in immunofluorescence assays is demonstrated in Supplementary Figure S1.

Generation of mice with a phosphorylation mutant allele of Smc1 (Smc1 ${ }^{\text {S957AS966A) }}$

An Smc1 targeting vector, pSmc1KI-Neotk was constructed as described below in a yeast vector pRS423 (gift of P. Hieter, University of British Columbia, Vancouver, BC, Canada). Approximately $10 \mathrm{~kb}$ of mouse genomic region containing exons 17,18 , and 19 of the $S m c 1$ gene was PCR amplified from genomic DNA isolated from a mouse ES cell line W9.5, then cloned in pRS423. A loxP-flanked Neo-tk cassette (containing a Neomycine-resistant gene for positive selection, and a thymidine kinase gene for negative selection) was PCR amplified from a vector pNeoloxP, then inserted into a site between exons 18 and 19. Two nucleotide exchanges to change serine to alanine at amino acid positions 957 and 966 were made in exon 19 by the yeast homologous recombination (Kitagawa and Abdulle 2002). The absence of mutations in exons 17,18 , and 19 were confirmed by sequencing.

W9.5 ES cells were electroporated with PvuII-linealized pSmc1KI-Neotk and selected in ES medium containing G418. Genomic DNA from 400 G418-resistant colonies were screened for homologous recombination at the Smc1 locus by Southern blot hybridization with an external probe. Isolated targeted clone was electroporated with pMC-Cre, a Cre recombinase expression vector, and selected in ES medium containing gancy- 
clovir. Removal of the loxP-flanked Neotk cassette was confirmed by genomic PCR with flanking primers. ES cells with a

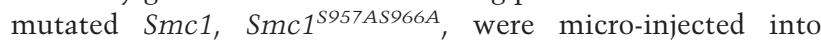
C57BL/6 blastocysts, which were then transferred into psuedopregnant mother mice. Chimeric male mice identified by the presence of agouti coat color, were mated to 129 S females, and transmission of the targeted allele through the germ line was determined by coat color. Mice heterozygous for the targeted allele were intercrossed to generate $S m c 1^{\text {S957AS966A }}$ homozygotes.

Establishment of Smc1 ${ }^{\text {S957AS966A }}$ MEF cultures or Smc1 ${ }^{\text {S957AS966A }}$ skin fibroblast cell cultures

Individual embryos from an $S m c 1^{\text {S957AS966A/+ }}$ mouse mated with an $\mathrm{Smc1}^{\text {S957AS966A/- }}$ mouse at $13.5 \mathrm{dpc}$ were dissected from the deciduum in PBS, mechanically disrupted in $100 \mu \mathrm{L}$ of $0.25 \%$ trypsin by chopping with a fine razor, then passing through 20G needles, and placed into individual $3.5-\mathrm{cm}$ dishes in MEF medium. Cells hemizygous for Smc1 ${ }^{\text {S957AS966A }}$ were maintained. Cells hemizygous for wild-type Smc1 were also maintained as counterparts.

Sections of mouse skin (2-mm square) dissected from a dorsal region of a mouse hemizygous for $S m c 1^{S 957 A S 966 A}$ were stuck on the bottom of $3.5-\mathrm{cm}$ dishes by giving a pressure over the coverglass, and immersed in MEF medium containing $20 \%$ FBS. After proliferating cells expanded around the skin section to fill a $3.5-\mathrm{cm}$ dish, the concentration of serum in culture medium was reduced to $10 \%$, and the cells were subsequently maintained on a $3 \mathrm{~T} 3$ culture protocol.

\section{Chromosome aberration assay}

Preparation of metaphase spreads, chromosome staining, and counting of chromosome aberrations were performed by the Cytogenetics lab in the Department of Genetics at St. Jude Children's Research Hospital. Briefly, MEF cells were treated with corcemid for $4 \mathrm{~h}$ at various time points following cellular irradiation. Numbers of chromosome breaks, chromosome gaps, chromatid breaks, and chromatid gaps were scored in 100 metaphase spreads per sample.

\section{Cell-survival assay}

Sensitivity to DNA-damage agents was assessed by seeding $1 \times 10^{5}$ cells into individual gelatinized wells of a 6-well dish in triplicate and treating the cultures the following day. For IR treatment, cells were irradiated with a ${ }^{137} \mathrm{Cs}$ source at a dose rate of $\sim 120 \mathrm{cGy} / \mathrm{min}$. For methylmethane sulfonate (MMS) treatment, cells were cultured in medium containing MMS for $1 \mathrm{~h}$, then the medium was removed and replaced with fresh medium lacking MMS. Seventy-two hours after treatment, cells were harvested by trypsinization, stained with trypan blue dye, and counted.

\section{Acknowledgments}

We thank Diane Woods, Margaret Reis, Heather Briley, Helen Russell, and Youngsoo Lee for excellent technical assistance or advice. This work was supported by grants from the NIH (CA93632, CA71387, and CA21765) and by the American Lebanese Syrian Associated Charities (ALSAC) of the St. Jude Children's Research Hospital.

The publication costs of this article were defrayed in part by payment of page charges. This article must therefore be hereby marked "advertisement" in accordance with 18 USC section 1734 solely to indicate this fact.

\section{References}

Alligood, K.J., Milla, M., Rhodes, N., Ellis, B., Kilpatrick, K.E., Lee, A., Gilmer, T.M., and Lansing, T.J. 2000. Monoclonal antibodies generated against recombinant ATM support kinase activity. Hybridoma 19: 317-321.

Bakkenist, C.J. and Kastan, M.B. 2003. DNA damage activates ATM through intermolecular autophosphorylation and dimer dissociation. Nature 421: 499-506.

Banin, S., Moyal, L., Shieh, S., Taya, Y., Anderson, C.W., Chessa, L., Smorodinsky, N.I., Prives, C., Reiss, Y., Shiloh, Y., et al. 1998. Enhanced phosphorylation of p53 by ATM in response to DNA damage. Science 281: 1674-1677.

Canman, C.E., Wolff, A.C., Chen, C.Y., Fornace Jr., A.J., and Kastan, M.B. 1994. The p53-dependent G1 cell cycle checkpoint pathway and ataxia-telangiectasia. Cancer Res. 54: 5054-5058.

Canman, C.E., Lim, D.S., Cimprich, K.A., Taya, Y., Tamai, K., Sakaguchi, K., Appella, E., Kastan, M.B., and Siliciano, J.D. 1998. Activation of the ATM kinase by ionizing radiation and phosphorylation of p53. Science 281: 1677-1679.

Carson, C.T., Schwartz, R.A., Stracker, T.H., Lilley, C.E., Lee, D.V., and Weitzman, M.D. 2003. The Mre11 complex is required for ATM activation and the $G(2) / M$ checkpoint. EMBO I. 22: 6610-6620.

Chen, H.T., Bhandoola, A., Difilippantonio, M.J., Zhu, J., Brown, M.J., Tai, X., Rogakou, E.P., Brotz, T.M., Bonner, W.M., Ried, T., et al. 2000. Response to RAG-mediated VDJ cleavage by NBS1 and gamma-H2AX. Science 290: 19621965.

Cortez, D., Wang, Y., Qin, J., and Elledge, S.J. 1999. Requirement of ATM-dependent phosphorylation of brcal in the DNA damage response to double-strand breaks. Science 286: $1162-1166$.

Ganesan, S., Silver, D.P., Greenberg, R.A., Avni, D., Drapkin, R., Miron, A., Mok, S.C., Randrianarison, V., Brodie, S., Salstrom, J., et al. 2002. BRCA1 supports XIST RNA concentration on the inactive X chromosome. Cell 111: 393-405.

Garg, R., Callens, S., Lim, D-S., Canman, C.E., Kastan, M.B., and $\mathrm{Xu}, \mathrm{B} .2004$. The Rad17-Atr-Smc1 pathway is essential for ultraviolet radiation induced S-phase arrest. Mol. Cancer Res. (in press).

Girard, P.M., Riballo, E., Begg, A.C., Waugh, A., and Jeggo, P.A. 2002. Nbs1 promotes ATM dependent phosphorylation events including those required for $\mathrm{G} 1 / \mathrm{S}$ arrest. Oncogene 21: 4191-4199.

Horejsi, Z., Falck, J., Bakkenist, C., Kastan, M., Lukas, J., and Bartek, J. 2004. Distinct functional domains of Nbs1 modulate the timing and magnitude of ATM activation after low doses of ionizing radiation. Oncogene 23: 3122-3127.

Jessberger, R., Podust, V., Hubscher, U., and Berg, P. 1993. A mammalian protein complex that repairs double-strand breaks and deletions by recombination. J. Biol. Chem. 268: 15070-15079.

Jessberger, R., Riwar, B., Baechtold, H., and Akhmedov, A.T. 1996. SMC proteins constitute two subunits of the mammalian recombination complex RC-1. EMBO J. 15: 4061-4068.

Kastan, M.B. and Lim, D.S. 2000. The many substrates and functions of ATM. Nat. Rev. Mol. Cell. Biol. 1: 179-186.

Kim, S.T., Xu, B., and Kastan, M.B. 2002. Involvement of the cohesin protein, $\mathrm{Smc1}$, in Atm-dependent and independent responses to DNA damage. Genes \& Dev. 16: 560-570. 
Kitagawa et al.

Kitagawa, K. and Abdulle, R. 2002. In vivo site-directed mutagenesis of yeast plasmids using a three-fragment homologous recombination system. Biotechniques 33: 288, 290, 292 passim.

Lee, J.H. and Paull, T.T. 2004. Direct activation of the ATM protein kinase by the Mre11/Rad50/Nbs1 complex. Science 304: 93-96.

Lee, J.H., Xu, B., Lee, C.H., Ahn, J.Y., Song, M.S., Lee, H., Canman, C.E., Lee, J.S., Kastan, M.B., and Lim, D.S. 2003. Distinct functions of Nijmegen breakage syndrome in ataxia telangiectasia mutated-dependent responses to DNA damage. Mol. Cancer Res. 1: 674-681.

Lim, D.S., Kim, S.T., Xu, B., Maser, R.S., Lin, J., Petrini, J.H., and Kastan, M.B. 2000. ATM phosphorylates p95/nbs1 in an Sphase checkpoint pathway. Nature 404: 613-617.

Matsuoka, S., Rotman, G., Ogawa, A., Shiloh, Y., Tamai, K., and Elledge, S.J. 2000. Ataxia telangiectasia-mutated phosphorylates Chk2 in vivo and in vitro. Proc. Natl. Acad. Sci. 97: 10389-10394.

Michaelis, C., Ciosk, R., and Nasmyth, K. 1997. Cohesins: Chromosomal proteins that prevent premature separation of sister chromatids. Cell 91: 35-45.

Mirzoeva, O.K. and Petrini, J.H. 2001. DNA damage-dependent nuclear dynamics of the Mrell complex. Mol. Cell. Biol. 21: 281-288.

2003. DNA replication-dependent nuclear dynamics of the Mre11 complex. Mol. Cancer Res. 1: 207-218.

Mochan, T.A., Venere, M., DiTullio Jr., R.A., and Halazonetis, T.D. 2003. 53BP1 and NFBD1/MDC1-Nbs1 function in parallel interacting pathways activating ataxia-telangiectasia mutated (ATM) in response to DNA damage. Cancer Res. 63: $8586-8591$.

Morgan, S.E., Lovly, C., Pandita, T.K., Shiloh, Y., and Kastan, M.B. 1997. Fragments of ATM which have dominant-negative or complementing activity. Mol. Cell. Biol. 17: 20202029.

Nakada, D., Matsumoto, K., and Sugimoto, K. 2003. ATM-related Tell associates with double-strand breaks through an Xrs2-dependent mechanism. Genes \& Dev. 17: 1957-1962.

Pandita, T.K. and Hittelman, W.N. 1992. The contribution of DNA and chromosome repair deficiencies to the radiosensitivity of ataxia-telangiectasia. Radiat. Res. 131: 214-223.

Ruffner, H. and Verma, I.M. 1997. BRCA1 is a cell cycle-regulated nuclear phosphoprotein. Proc. Natl. Acad. Sci. 94: 7138-7143.

Shiloh, Y. and Kastan, M.B. 2001. ATM: Genome stability, neuronal development, and cancer cross paths. Adv. Cancer Res. 83: 209-254.

Siliciano, J.D., Canman, C.E., Taya, Y., Sakaguchi, K., Appella, E., and Kastan, M.B. 1997. DNA damage induces phosphorylation of the amino terminus of p53. Genes \& Dev. 11: 34713481.

Sjogren, C. and Nasmyth, K. 2001. Sister chromatid cohesion is required for postreplicative double-strand break repair in Saccharomyces cerevisiae. Curr. Biol. 11: 991-995.

Slichenmyer, W.J., Nelson, W.G., Slebos, R.J., and Kastan, M.B. 1993. Loss of a p53-associated G1 checkpoint does not decrease cell survival following DNA damage. Cancer Res. 53: 4164-4168.

Smilenov, L.B., Morgan, S.E., Mellado, W., Sawant, S.G., Kastan, M.B., and Pandita, T.K. 1997. Influence of ATM function on telomere metabolism. Oncogene 15: 2659-2665.

Stursberg, S., Riwar, B., and Jessberger, R. 1999. Cloning and characterization of mammalian SMC1 and SMC3 genes and proteins, components of the DNA recombination complexes RC-1. Gene 228: 1-12.
Taniguchi, T., Garcia-Higuera, I., Xu, B., Andreassen, P.R., Gregory, R.C., Kim, S.T., Lane, W.S., Kastan, M.B., and D'Andrea, A.D. 2002. Convergence of the fanconi anemia and ataxia telangiectasia signaling pathways. Cell 109: 459472.

Theunissen, J.W., Kaplan, M.I., Hunt, P.A., Williams, B.R., Ferguson, D.O., Alt, F.W., and Petrini, J.H. 2003. Checkpoint failure and chromosomal instability without lymphomagenesis in Mre11(ATLD1/ATLD1) mice. Mol. Cell 12: 15111523.

Uziel, T., Lerenthal, Y., Moyal, L., Andegeko, Y., Mittelman, L., and Shiloh, Y. 2003. Requirement of the MRN complex for ATM activation by DNA damage. EMBO J. 22: 5612-5621.

Wu, X., Petrini, J.H., Heine, W.F., Weaver, D.T., Livingston, D.M., and Chen, J. 2000. Independence of $\mathrm{R} / \mathrm{M} / \mathrm{N}$ focus formation and the presence of intact BRCA1. Science 289: 11 .

$\mathrm{Xu}, \mathrm{B} ., \mathrm{Kim}, \mathrm{S}$., and Kastan, M.B. 2001. Involvement of Brcal in S-phase and G(2)-phase checkpoints after ionizing irradiation. Mol. Cell. Biol. 21: 3445-3450.

Xu, B., Kim, S.T., Lim, D.S., and Kastan, M.B. 2002. Two molecularly distinct $\mathrm{G}(2) / \mathrm{M}$ checkpoints are induced by ionizing irradiation. Mol. Cell. Biol. 22: 1049-1059.

Yazdi, P.T., Wang, Y., Zhao, S., Patel, N., Lee, E.Y., and Qin, J. 2002. SMC1 is a downstream effector in the ATM/NBS1 branch of the human S-phase checkpoint. Genes \& Dev. 16: $571-582$.

Zhou, B.B. and Elledge, S.J. 2000. The DNA damage response: Putting checkpoints in perspective. Nature 408: 433-439. 


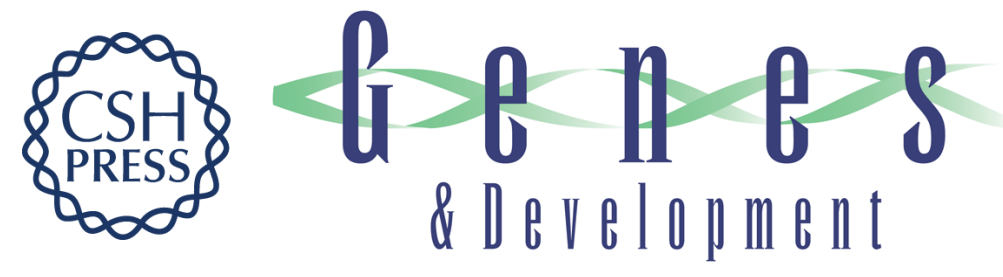

\section{Phosphorylation of SMC1 is a critical downstream event in the ATM- NBS1-BRCA1 pathway}

Risa Kitagawa, Christopher J. Bakkenist, Peter J. McKinnon, et al.

Genes Dev. 2004, 18:

Access the most recent version at doi:10.1101/gad.1200304

\section{Supplemental http://genesdev.cshlp.org/content/suppl/2004/06/03/1200304.DC1 Material}

References This article cites 41 articles, 23 of which can be accessed free at: http://genesdev.cshlp.org/content/18/12/1423.full.html\#ref-list-1

\section{License}

Email Alerting

Receive free email alerts when new articles cite this article - sign up in the box at the top Service

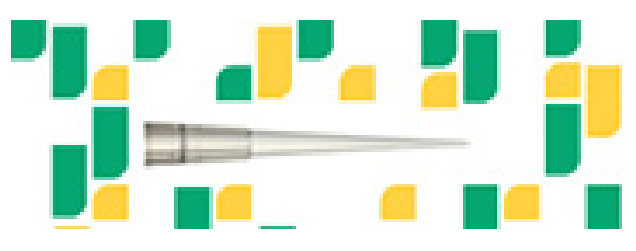

